\title{
A Theoretical Study of the Phosphoryl Transfer Reaction from ATP to Dha Catalyzed by DhaK from Escherichia coli
} \author{
Spain. \\ * to whom correspondence should be addressed: \\ R. Castillo: rcastill@uji.es \\ V. Moliner: moliner@uji.es \\ ORCID: \\ R. Castillo: 0000-0003-1597-1136 \\ V. Moliner: 0000-0002-3665-3391
}

I. Bordes, ${ }^{1}$ R. Castillo ${ }^{1, *}$ and V. Moliner ${ }^{1,2, *}$

1. Departament de Química Física i Analítica, Universitat Jaume I, 12071Castellón,

2. Department of Chemistry, University of Bath, Bath BA2 7AY, United Kingdom. 


\begin{abstract}
Protein kinases, representing one of the largest protein family involved in almost all aspects of cell life, have become one of the most important targets for the development of new drugs to be used in, for instance, cancer treatments. In this paper an exhaustive theoretical study of the phosphoryl transfer reaction from adenosine triphosphate (ATP) to dihydroxyacetone (Dha) catalyzed by DhaK from Escherichia coli (E. coli) is reported. Two different mechanisms, previously proposed for the phosphoryl transfer from ATP to the hydroxyl side chain of specific serine, threonine or tyrosine residues, have been explored based on the generation of free energy surfaces (FES) computed with hybrid QM/MM potentials. The results suggest that the substrate-assisted phosphoryl and proton-transfer mechanism is kinetically more favorable than the mechanism where an aspartate would be activating the Dha. Although the details of the mechanisms appear to be dramatically dependent on the level of theory employed in the calculations (PM3/MM, B3LYP:PM3/MM or B3LYP/MM), the transition states (TSs) for the phosphoryl transfer step appear to be described as a concerted step with different degrees of synchronicity in the breaking and forming bonds process in both explored mechanisms. Residues of the active site belonging to different subunits of the protein such as Gly78B, Thr79A, Ser80A, Arg178B and one $\mathrm{Mg}^{2+}$ cation would be stabilizing the transferred phosphate in the TS. Asp109A would have a structural role by posing the Dha and other residues of the active site in the proper orientation. The information derived from our calculations not only reveals the role of the enzyme and the particular residues of its active site, but it can assist in the rationally design of new more specific inhibitors.
\end{abstract}




\section{INTRODUCTION}

The transfer of a phosphoryl group from an ester or anhydride to a nucleophile ${ }^{1}$ is involved in many processes taking place in the cells of living organisms, playing and essential role in propagation and signal transduction. ${ }^{2-5}$ Protein kinases catalyze the transfer of phosphate groups to different substrates in cells, being the adenosine triphosphate (ATP) the most important biological phosphoryl donor. An indication of the relevance of kinases is the fact that there are more than 500 protein kinases encoded in the human genome. In addition, it has been found around 540 kinases in mice and 122 in yeast, representing one of the largest protein family. ${ }^{6}$ Numerous kinases are closely involved in cancer progression. ${ }^{7,8}$ The common feature maintained throughout protein kinase family is the sharing of a highly conserved catalytic center, making possible that one inhibitor molecule could bind to several kinases, blocking regular signaling needed for normal cellular function. However, it is also feasible that the capability of interfering in a multitude of kinases could be beneficial in cancer treatments, provided that the inhibitor is specific to cancerous cells. ${ }^{2,3}$ During the last years many studies have been focused on drug research related with kinases and several small-molecule kinase inhibitor drugs have been approved for the treatment of different cancers. $^{9,10}$ Even so, despite its relevance for cellular control and their crucial contribution in modern medical techniques, the entire protein phosphorylation network has not been investigated deeply. ${ }^{8}$

Previous theoretical studies on phosphoryl transfer reactions have stressed the presence of low-lying d-orbitals on the phosphorus atoms that allows the existence of phosphorus pentavalent species as intermediates. ${ }^{11-14}$ The reaction of phosphate transfers has been considered to occur through two alternative mechanisms; ${ }^{15,16}$ associative, in which nucleophilic attack precedes the living group departure, and dissociative, in which departure of the living group takes place before the nucleophilic attack is produced. The reaction can in turn proceed through only one step but it does not necessarily imply a synchronous forming and breaking bonds process since associative-like or dissociativelike mechanism can be observed for concerted paths. Different computational studies of ATP hydrolysis indicate the dissociative mechanism energetically more favorable than the associative one. ${ }^{17-19}$ Others show very small energetic difference between the associative, dissociative and concerted mechanisms. ${ }^{20}$ And more recently, different 
QM/MM studies ${ }^{21-22}$ of the ATP hydrolysis in myosin indicates the flexibility of the hydrolysis mechanism of this enzyme which presented similar free energies, and the dissociative mechanism like the most favorable within a metaphosphate compound.

In addition, studies of guanosine triphosphate (GTP) hydrolysis catalyzed by different GTPases concluded that different types of GTP hydrolysis reaction pathways can be obtained in each system which indicates that enzymes catalyzing GTP hydrolysis are able to stabilize different transition states modulating the reaction path. ${ }^{23,24}$

Studies of the phosphate transfer from ATP to serine or tyrosine residues in protein kinases have been also widely reported. ${ }^{3,25-31}$ Thus, a theoretical study in cyclindependent kinase (CDK2) by De Vivo et al. ${ }^{25}$ proposed that an Asp residue located in the active site would play a structural role whereas the activation of the Ser nucleophile was proposed to be due to a proton transfer to ATP. The authors suggested a substrateassisted mechanism through a single concerted transition state (TS). Smith and coworkers studied the phosphoryl transfer reaction to a Ser residue catalyzed by a CDK2 using QM/MM methods. ${ }^{3}$ Their results support a concerted dissociative mechanism through a metaphosphate-like TS, where an Asp residue, rather than ATP as previously proposed, would be acting as the general base to activate the Ser nucleophile. They associated the conclusions of De Vivo et al. to the exclusion of the Asp from the QM region. Based also on $\mathrm{QM} / \mathrm{MM}$ methods and classical MD simulations, a similar catalytic mechanism was suggested by Ojeda-May et al. in insulin receptor kinase (IRK). ${ }^{26}$ In this case, a catalytic Asp residue would abstract the proton from a Tyr residue of the substrate peptide. Diaz and Field suggested the same catalytic role for Asp residue from DFT calculations on a cluster model of the active site of cAMPdependent protein kinase (PKA), where the ATP phosphate would be transferred to a Ser side chain residue. ${ }^{30}$ Later, Cheng and co-workers conducted combined ab initio QM/MM methods in the same enzyme supported likewise the role of the Asp residue as a catalytic base and describing the reaction mechanism as mainly dissociative. ${ }^{31}$ Even so, the previously performed work of Hart et al. ${ }^{27}$ supported the substrate-assisted reaction as well, since they obtained higher potential energy barriers when the proton was transferred from Ser to Asp in PKA. More recently, based on the generation of QM/MM PESs, Pérez-Gallegos et al. ${ }^{28,29}$ analyzed the phosphate transfer from ATP to a Ser residue catalyzed by PKA and concluded that the catalytic mechanism was not substrate dependent, with the active site Asp acting as a general acid-base catalyst. 
Another important debate on phosphate transfer reactions of ATP is the role of the two magnesium ions that appear in the active site of kinases. It has been proposed that they are useful not only to stabilize ATP binding but also to accelerate the chemical reaction. ${ }^{32,33}$ These metal ions have been reported to be greatly important to stabilize the negative charges accumulated during the phosphate transfer and before. ${ }^{34,3}$ Its indispensability in many enzymatic systems has motivated several authors to determine the specific roles of $\mathrm{Mg}^{2+}$ in catalysis. Nevertheless, as stated by Lopata et al., despite the indispensability of the metal ion in most phosphoryl transfer and hydrolysis catalyzing enzymes, its role was not completely clear. ${ }^{35}$

Dihydroxyacetone kinases (DhaK) belong to a family of sequence-conserved enzymes that phosphorylate dihydroxyacetone (Dha) converting it in dihydroxyacetone phosphate (Dha-P). ${ }^{34,36-38}$ Dha-P is an intermediate for the synthesis of pyruvate ${ }^{34}$ and it is a very valuable compound in nature since it is used as phosphoryl donor in several enzyme-catalyzed aldol reactions for the formation of C-C bonds. ${ }^{39,40}$ DhaK from Escherichia coli (E. coli), the most characteristic of the PTS-dependent DhaKs, is constituted by DhaK, DhaL and DhaM subunits. ${ }^{41}$ The reaction starts with phosphorylation of DhaM, by the small phospho-carrier protein HPr of the PTS. Phosphorylated DhaM forms a complex with the ADP-bound DhaL subunit and transfers the phosphate to ADP turning it into ATP. Then, the ATP linked DhaL associates with DhaK subunit, which enclose the Dha compound bounded through a hemiaminal bond to His218. Finally, phosphate is transferred from ATP to Dha yielding as the product of the reaction, Dha-P and ADP..$^{34,38,41,42}$

The molecular mechanism of the enzyme catalyzed phosphate transfer from ATP to Dha has been proposed based on the crystal structure of the E. coli DhaK-DhaL complex bound to ADP and Dha determined by Shi and co-workers. ${ }^{34}$ The analysis of experimental results allows them to present a general catalytic mechanism for DhaK in which residues His56, His218 and Asp109 would be significantly involved in the reaction progress. In particular, they divided the whole reaction in three stages: 1) binding of Dha to enzyme through a hemiaminal bond with His218, acting the His56 as an acid donating its proton to Dha substrate; 2) Phosphate transfer from ATP to Dha where Asp109 acts as a base in order to prepare the Dha for the attack; and 3) release of the reaction product, Dha-P, from the enzyme. ${ }^{34}$

Nevertheless, and despite the great contributions to the study of kinases, the explicit reaction between ATP and Dha in DhaK from E.coli has not been studied by means of 
computational methods. The analysis of the reaction by computational tools in DhaK can provide a better understanding of the behavior of these enzymes and a valuable contribution to clarify the molecular mechanism of phosphoryl transfer reactions. The recent $\mathrm{QM} / \mathrm{MM}$ computational study of the counterpart reaction in aqueous solution carried out in our laboratory can be used to establish the methodological basis for the study of the reaction in the active site of DhaK and to estimate its catalytic efficiency. ${ }^{43}$ In the present paper, we present an exhaustive theoretical study of the phosphoryl transfer reaction from ATP to Dha catalyzed by DhaK from E. coli. The possible reaction mechanisms are described based on the exploration of Free Energy Surfaces (FESs) computed by means of MD simulations with hybrid QM/MM potentials. The information derived from the calculations will allow not only revealing the role of the enzyme and the particular residues of the active site, but can have potential applications in the rational design of new more specific inhibitors.

\section{COMPUTATIONAL METHODS}

The initial coordinates were taken from the X-ray structure of E. coli DhaK, with PDB entry 3PNL. ${ }^{34}$ This structure has two domains, DhaK and DhaL, differentiated as chain A and chain B. The chain A has 356 amino acids and the glycerol substrate while chain B contains 211 amino acids, ADP and two magnesium ions. The original ADP molecule was modified to ATP by adding a phosphate group manually within the help of Molden program $^{44}$. The glycerol molecule was modified to Dha changing one alcohol functional group by a ketone group.

The protonation state of titratable residues has been determined using the PropKa program of Jensen et al. ${ }^{45,46}$ at $\mathrm{pH}=7$. According to the results, all residues were found at their standard protonation state in aqueous solution, except His56A that had to be double protonated. The coordinates of the hydrogen atoms were added using the fDYNAMO library. ${ }^{47}$ Then, 21 sodium ions were added to neutralize the negative charges of the system. Afterwards, the system was solvated with a pre-equilibrated orthorhombic box of water molecules with dimensions 100x80x80 $\AA^{3}$. Water molecules with an oxygen atom lying within $2.8 \AA$ of any heavy atom of ATP, Dha or protein were removed. The resulting system consists in 62823 atoms.

Once the model was generated, in order to relax energetically unfavorable interactions, series of optimizations using the conjugate gradient method followed by $5 \mathrm{~ns}$ of 
classical MD simulations in the NVT ensemble at a temperature of $300 \mathrm{~K}$ using the Langevin-Verlet algorithm using a time step of 1 fs. The OPLS-AA force field, ${ }^{48}$ and the TIP3P $\mathrm{P}^{49}$ force fields, as implemented in NAMD parallel molecular dynamics code, ${ }^{50}$ were used to describe the protein and the water molecules, respectively. Parameters for Dha were generated with the ParamChem application ${ }^{51,52}$ while parameters from the CHARMM general force field v. $2 b 7^{53}$ were used for the ATP. Cut-offs for nonbonding interactions between atoms were applied using a switching-force scheme, within a range radius from 12 to $15 \AA$ with periodic boundary conditions. The time evolution of the RMSD of the backbone atoms of the enzyme as well as the RMSD computed for just the backbone atoms of the active site residues (those in a radios sphere of $8 \AA$ ) during 5 ns of MD simulations show that the system can be considerate as equilibrated after the MD simulations (see Figures S1 and S2 of Supporting Information). This conclusion is supported by the inspection of the time evolution of individual key interactions established in the active site during the equilibration MD simulation (see Figures S3, S4 and S5 of Supporting Information). The resulting system was taken as the initial structure for the following QM/MM calculations. The Dha molecule, part of ATP (phosphate groups and ribose ring), the side chains of residues involved in the reaction mechanism (His218A, His56A and Asp109A), the magnesium ions and part of the residues in the coordination sphere of these magnesium ions (Asp30B, Asp35B, Asp37B, Phe78A and Thr79A) were treated quantum mechanically (see Scheme 1). The rest of the atoms of the protein and the water molecules were treated by means of the OPLS-AA and TIP3P ${ }^{49}$ force field, respectively. To saturate the valence of the QM/MM frontier we used the link atom procedure ${ }^{54}$, placing this atom between $\mathrm{C}$ of the ribose molecule and $\mathrm{N}$ of the adenine molecule in the case of ATP, between $\mathrm{C}_{\alpha}$ and $\mathrm{C}_{\beta}$ in aspartate and histidine residues, between carboxyl carbon and $\mathrm{C}_{\alpha}$ in Phe78A and between amino nitrogen and $\mathrm{C}_{\alpha}$ in Thr79A (see Scheme 1). Thus, the QM part involves 96 atoms with a total charge of -3 .

For all simulations, any residues further than $25 \AA$ from the $\mathrm{O}_{\mathrm{B} 3}$ oxygen atom of ATP were kept frozen during the simulations. As well as in NAMD calculations, cut-offs for nonbonding interactions were applied using a switching function, within a radius range from 12.0 to $15.0 \AA$ A , employing periodic boundary conditions. 


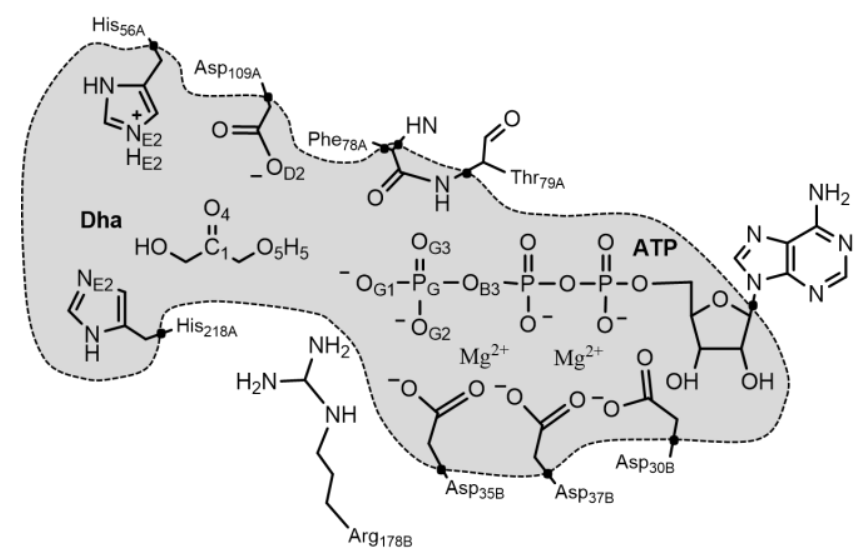

Scheme 1. Schematic representation of the active site of the DhaK. Grey region contains atoms treated quantum mechanically. Link atoms are represented as black dots.

The OPLS-AA and TIP3P force fields, as implemented in fDYNAMO library, were used to describe the protein atoms of the MM region and the water molecules, respectively. The semiempirical Parameterized Method Number 3 (PM3) ${ }^{55}$, as implemented in fDYNAMO, was initially selected to treat the QM region during the QM/MM calculations. PM3 is typically 3-4 orders of magnitude faster than DFT methods and has been shown to produce a huge stabilization in the energy of phosphorane compounds, resulting from the use of a minimal valence basis. ${ }^{56}$ Therefore, it has been used extensively to successfully model phosphorus and phosphate groups. ${ }^{57-60}$ In fact, the semiempirical Hamiltonian PM3 was already tested to study the counterpart reaction in solution in our group, by means of QM/MM models, ${ }^{43}$ showing that optimized structures with PM3/MM method rendered structures with all P-O bonds with reasonable interatomic distances. It is important to point out that, despite AM1d/MM calculations provided more accurate energy values for the study of the reaction in solution, ${ }^{43}$ considering that the energies obtained at low-level (LL)/MM are later improved at high-level (HL)/MM with spline corrections (as explained below), we selected the PM3 Hamiltonian as the LL QM method due to the more reasonable structures obtained in the protein environment when combining with the MM force fields during the QM/MM MD simulations and energy optimizations.

In order to explore the full reaction mechanism of the DhaK catalysed reaction, PESs were first performed by scanning the appropriate combination of the interatomic distances to explore every single possible chemical step. Later FESs were computed in terms of potentials of mean force (PMFs). The umbrella sampling approach ${ }^{61}$ was used 
to constrain the system along the selected values of the reaction coordinates by employing a force constant of $2500 \mathrm{~kJ} \mathrm{~mol}^{-1} \AA^{-2}$. The value of the force constant used for the harmonic umbrella sampling were determined to allow full overlap of the different windows traced in the PMF evaluation, but without losing control over the selected coordinate. Each window consisted of 15 ps of equilibration followed by 20 ps of production. The Verlet algorithm was used to update the velocities. The initial structures in each window of the 2D-PMFs were selected from the corresponding previously generated PESs at the corresponding level of theory, whereas the 1D-PMFs were performed starting from the transition state structure. The probability distributions were put together by means of the weighted histogram analysis method (WHAM) ${ }^{62}$ to obtain the full probability distribution along the reaction coordinate.

The generation of FESs requires the evaluation of a large number of structures by means of QM/MM MD simulations. Consequently, calculations are usually restricted to the use of semiempirical Hamiltonians, as it is the case in the present study. In order to reduce the errors associated with the quantum low-level PM3 employed in our simulations, following the studies of Truhlar et al., ${ }^{63-65}$ an interpolated correction term was applied to any value of the reaction coordinate $\xi$, selected to generate the FES. Then, a continuous new energy function was generated that corrects the PMFs, as previously performed in our laboratory: ${ }^{66-68}$

$$
E=E_{L L / M M}+S\left[\Delta E_{L L}^{H L}(\xi)\right]
$$

where $\mathrm{S}$ denotes a spline under tension function, ${ }^{69,70}$ and its argument is a correction term evaluated from the single-point energy difference between a high-level (HL) and a low-level (LL) calculation of the QM subsystem. The semiempirical PM3 Hamiltonian was used as LL method, while the B3LYP method was selected for the HL energy calculation employing the $6-31 \mathrm{G}(\mathrm{d}, \mathrm{p})$ basis set. $\mathrm{S}$ is adjusted to a defined grid depending on the reaction step studied. HL single energy calculations are computed on optimized geometries obtained in the corresponding PESs at LL.

In those chemical steps explored by means of 2D-PMFs, the correction term is expressed as a function of two coordinates $\xi_{1}$ and $\xi_{2}$, being the new energy function:

$$
E=E_{L L / M M}+S\left[\Delta E_{L L}^{H L}\left(\xi_{1}, \xi_{2}\right)\right]
$$

In equation $2, \mathrm{~S}$ is adjusted to a set of points corresponding to the HL single energy calculations on geometries optimized at PM3 method, as previously explained. All the 
B3LYP calculations were carried by combining fDYNAMO with Gaussian09 program. $^{71}$

\section{RESULTS AND DISCUSSION}

As stated in the Introduction section, the aim of the work presented here is the study of the molecular mechanism of the phosphoryl transfer reaction from ATP to Dha catalyzed by DhaK. A detail of the active site of the starting structure in the reactant state, after equilibrated through QM/MM MD simulations as described in previous section, is shown in Figure 1. As observed in the figure, the reacting species are well oriented for the phosphoryl transfer. ATP is coordinated to the $\mathrm{Mg}^{2+}$ cations while Dha is stabilized by hydrogen bond interactions, mainly with Asp109A and His56A. The stability of these interactions is confirmed not only by the analysis of this snapshot but by the time evolution of these distances, as deposited in the Supporting Information. This initial structure was used as starting point to generate PESs for every chemical step involved in the mechanisms to be studied (PM3/MM PESs are deposited as Figures S3, S4 and S5 in the Supporting Information material).

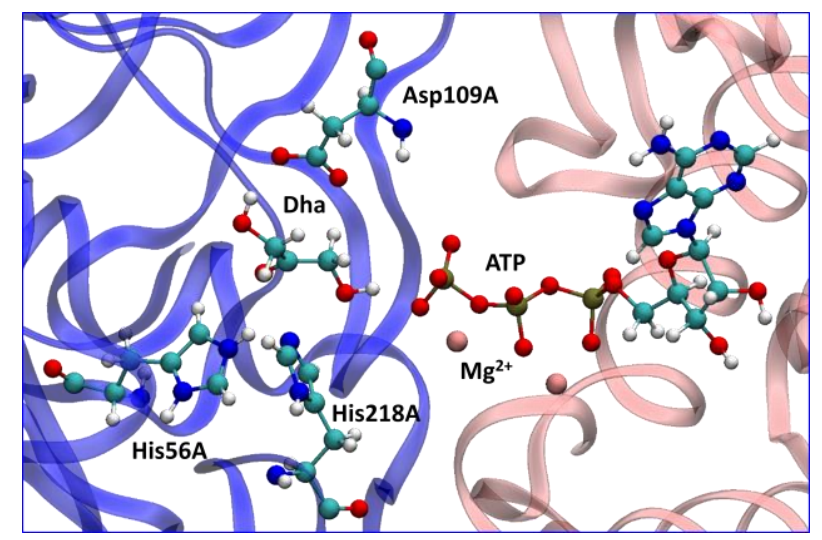

Figure 1. Representative snapshot of the active site of the DhaK in the reactants state after the QM/MM MD simulations. ATP, Dha, two $\mathrm{Mg}^{2+}$ ions and the key amino acids involved in the reaction mechanisms are shown as balls and sticks.

In the initial catalytic step, as depicted in Scheme 2, Dha is anchored to the enzyme through the formation of a covalent bond between the nitrogen atom NE2 of His218A and the carbon atom $\mathrm{C} 1$ of Dha. The nearby His56A acts as an acid, transferring the proton $\mathrm{HE} 2_{\mathrm{His} 56}$ to the oxygen atom $\mathrm{O} 4$ of Dha. The distance between nitrogen atom of His $218 \mathrm{~A}$ and the carbon atom of Dha, $\mathrm{d}\left(\mathrm{NE} 2{ }_{\mathrm{His} 218}-\mathrm{C} 1\right)$, and the antisymmetric 
combination of the distances describing the hydrogen transfer from His56A to Dha, $\mathrm{d}\left(\mathrm{NE} 2_{\mathrm{His} 56}-\mathrm{HE} 2_{\mathrm{Hsp} 56}\right)-\mathrm{d}\left(\mathrm{O} 4-\mathrm{HE} 2_{\mathrm{His} 56}\right)$, were used as distinguished reaction coordinates to generate a 2D-PMF. The resulting FESs at PM3/MM level and with spline corrections at B3LYP:PM3/MM level are shown in Figure 2a and 2b, respectively, while the free energy barriers are reported in Scheme 2.

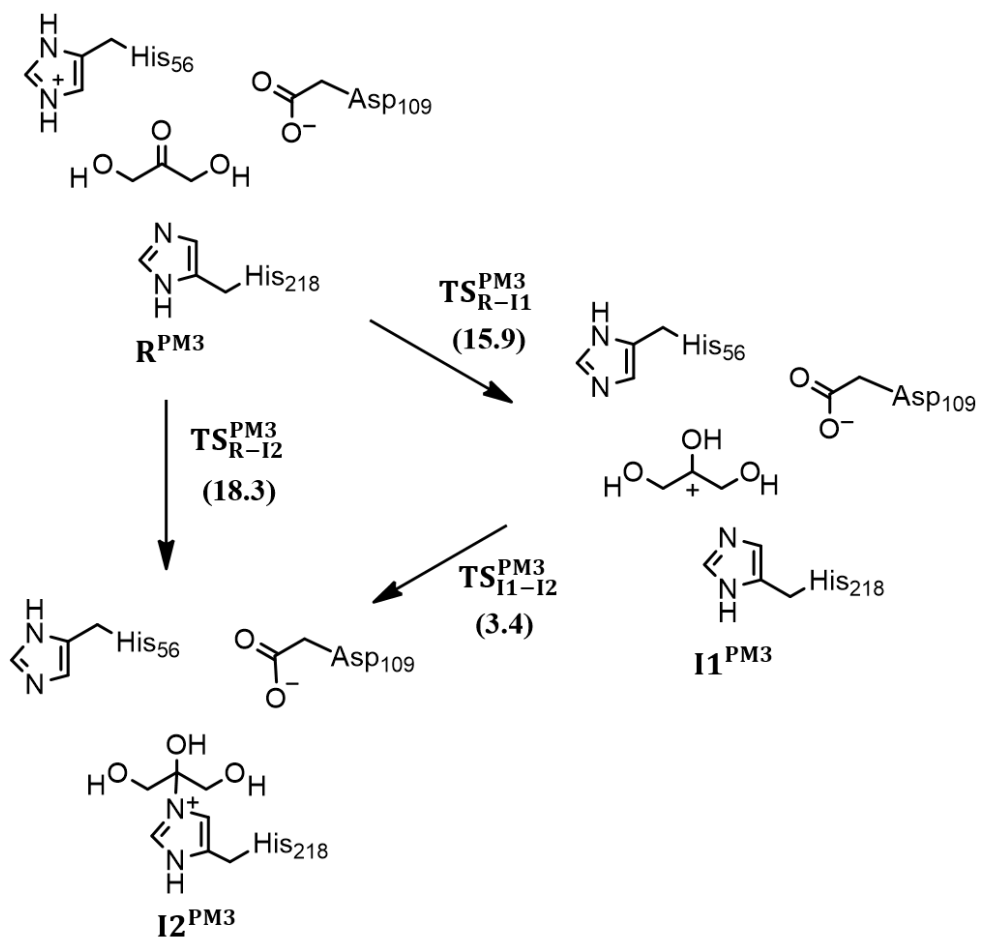

Scheme 2. Schematic representation of the initial step of the phosphorylation reaction mechanism corresponding to the formation of a covalent bond between Dha and the enzyme DhaK from E. coli. Values of the free energies barriers computed at PM3/MM level, in $\mathrm{kcal} \cdot \mathrm{mol}^{-1}$, are reported in brackets.

The analysis of Figure $2 \mathrm{a}$ reveals that the transformation from reactants to the intermediate $\mathrm{I} 2^{\mathrm{PM} 3}$ can take place through a stepwise or a concerted mechanism. In the former, first the proton from His56A is transferred to Dha, obtaining a stable intermediate $\mathrm{I}^{\mathrm{PM}}$. Then the formation of a covalent bond between Dha and His218A takes place through the $\mathrm{TS}_{\mathrm{I} 1-\mathrm{I} 2}^{\mathrm{PM} 3}$ reaching the intermediate $2^{\mathrm{PM} 3}$. The proton transfer can also take place concomitant with the $\mathrm{NE} 2_{\mathrm{His} 218} \mathrm{C} 1$ covalent bond formation through the concerted $\mathrm{TS}_{\mathrm{R}-\mathrm{I} 2}^{\mathrm{PM} 3}$. Analysis of the structure of $\mathrm{TS}_{\mathrm{R}-\mathrm{I} 2}^{\mathrm{PM} 3}$ shows that the bond formation between Dha and His218A is in a very advanced stage of the reaction (distance $\mathrm{NE} 2_{\mathrm{His} 218^{-}} \mathrm{C} 1_{\mathrm{Dha}}$ is $1.58 \AA$ ) while the transferring proton is located between its donor and 
acceptor atom (distances $\mathrm{NE} 2_{\mathrm{His} 56}-\mathrm{HE} 2_{\mathrm{His} 56}$ and $\mathrm{O} 4_{\mathrm{Dha}}-\mathrm{HE} 2_{\mathrm{His} 56}$ are 1.22 and $1.29 \AA$, respectively). A full list of the key interatomic distances of the located transition states on the FES are reported in Table S1 of the Supporting Information. From the energetic point of view, the free energy barrier of the rate limiting step of the stepwise mechanism, obtained at PM3/MM level, is only slightly lower than the concerted mechanism (15.9 and $18.3 \mathrm{kcal} \cdot \mathrm{mol}^{-1}$, respectively) suggesting the possibility of competitive mechanisms. Nevertheless, the corrected FES at B3LYP:PM3/MM level (Figure $2 \mathrm{~b}$ ) shows the absence of the intermediate $\mathrm{I} 1^{\mathrm{PM} 3}$, and the emergence of two concerted but very asynchronous mechanisms. Interestingly, the free energy barriers, 11.8 and $10.8 \mathrm{kcal} \cdot \mathrm{mol}^{-1}$, are significantly lower than the values obtained at PM3/MM level. The NE2-C1 bond is almost formed in the TS1 $1_{\mathrm{R}-\mathrm{I} 2}^{\mathrm{DFT}} \mathrm{PM}$ but the proton transfer from His56A to Dha is in an early stage of the process. By contrast, TS2 ${ }_{\mathrm{R}-\mathrm{I} 2}^{\mathrm{DF}} \mathrm{PM} 3$ describes a situation where the proton transfer is almost completed but the formation of the covalent bond between Dha and His218A is in an early stage of the process.
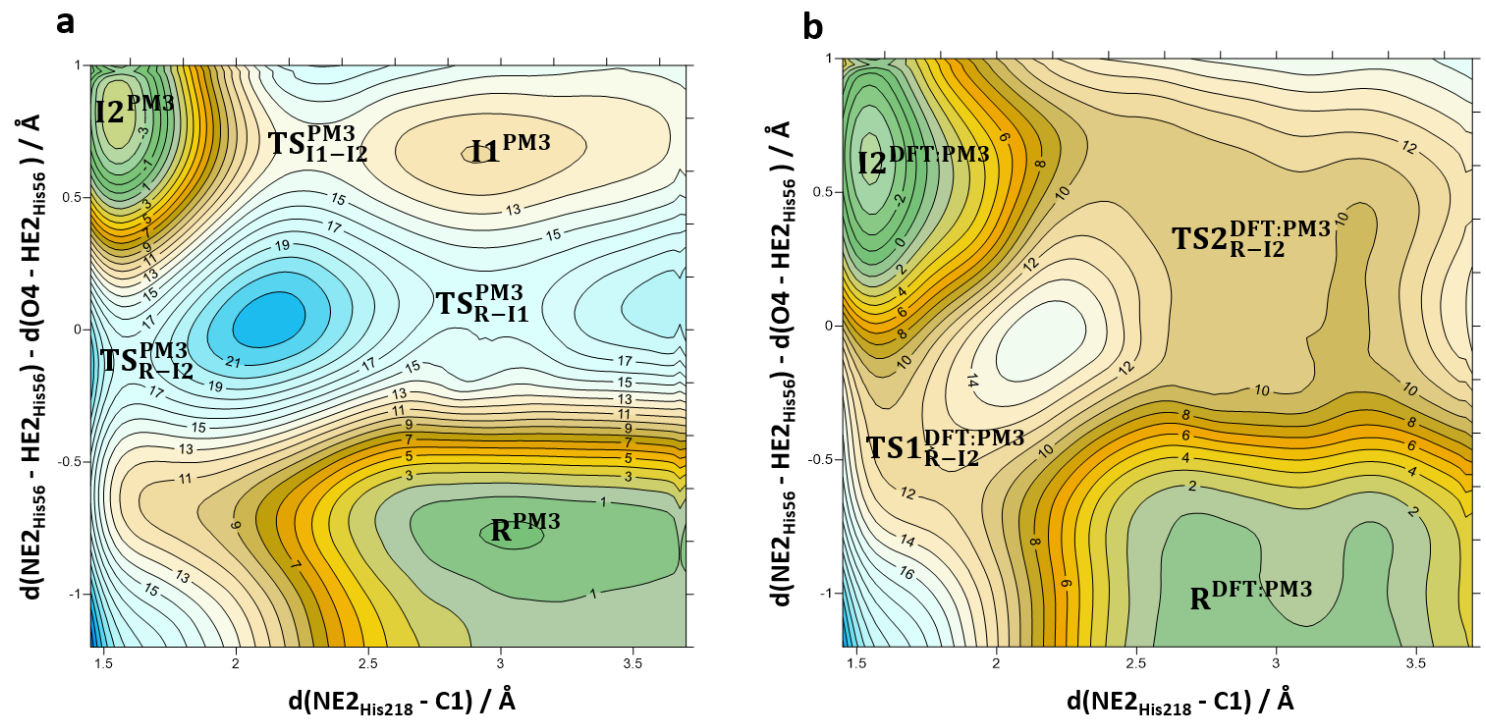

Figure 2. FESs of the first step of the phosphoryl transfer reaction from ATP to Dha catalyzed by DhaK from E. coli corresponding to the formation of a covalent bond between Dha and the enzyme. Surfaces obtained as 2D-PMFs at PM3/MM level (panel a) and with spline corrections at B3LYP:PM3/MM level (panel b). Values on the isoenergetic lines are in $\mathrm{kcal} \cdot \mathrm{mol}^{-1}$.

Then, after describing the first step of the DhaK in which the Dha is bounded to His218A (see Scheme 2), the rest of the reaction mechanism has been studied at three 
levels of theory, exploration of the FESs at PM3/MM, correction of the resulting FESs at DFT:PM3/MM level, and computing of PESs at DFT/MM level.

\section{PM3/MM FESs of the phosphorylation reaction.}

Once Dha is bounded to the enzyme (I2 $\left.{ }^{\mathrm{PM} 3}\right)$, the $\gamma-\mathrm{OH}$ group of Dha should be activated in order to make feasible the phosphate transfer from ATP. Thus, in the substrate-assisted mechanism the proton from Dha is directly transferred to the ATP whereas Asp109A has just a structural role (see Scheme 3). In the asp-assisted mechanism, Asp109A abstracts the proton from Dha and generates an oxyanion suitable for the attack of the ATP $\gamma$-phosphorus atom (see Scheme 4). As mentioned in the Introduction section, the first mechanism was supported by theoretical studies of the phosphoryl transfer reaction from ATP to the hydroxyl side chain of specific serine, threonine or tyrosine residues, while the later was proposed by Shi and co-workers based on crystal structures analysis. ${ }^{34}$ 
至

$12^{\text {PM3 }}$

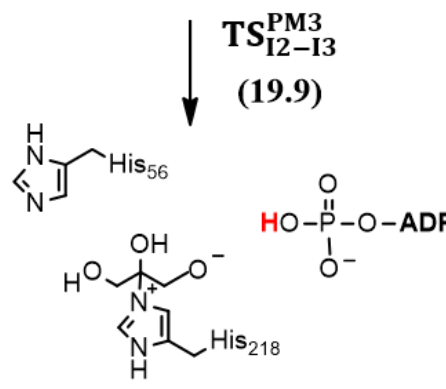

I3 ${ }^{\text {PM3 }}$

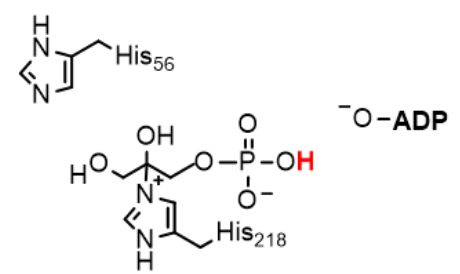

I4 ${ }^{\text {PM3 }}$

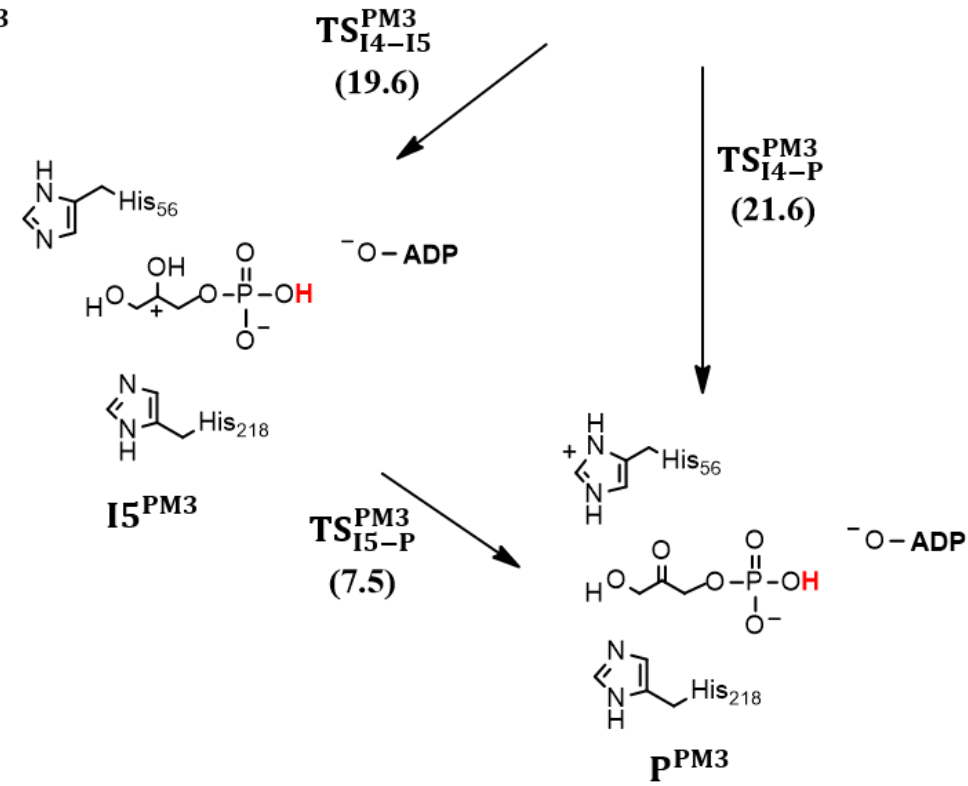

Scheme 3. Schematic representation of the substrate-assisted mechanism for the phosphorylation reaction from $\mathrm{I}^{\mathrm{PM} 3}$ intermediate to products, $\mathrm{P}^{\mathrm{PM} 3}$ in DhaK from $E$. coli obtained at PM3/MM level. Values of free energy barriers, in $\mathrm{kcal} \cdot \mathrm{mol}^{-1}$, are reported in brackets. 


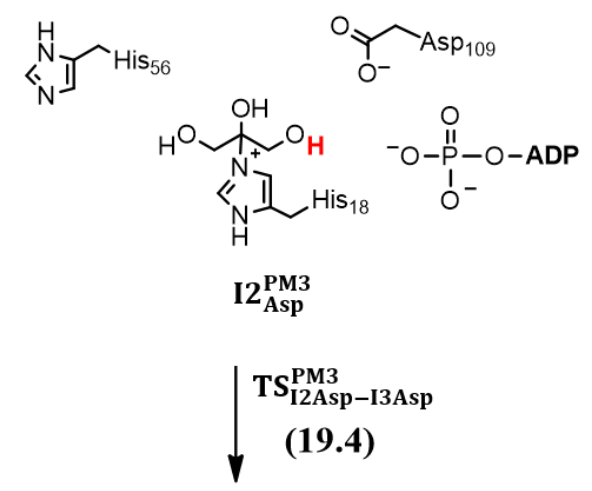

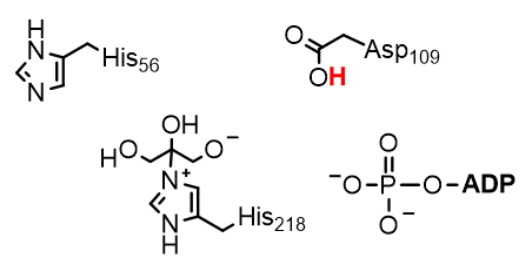

I3 $3_{\text {Asp }}^{\text {PM3 }}$

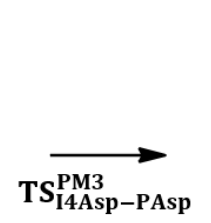

(21.5)

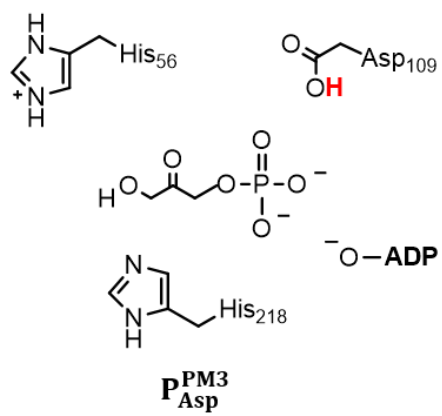

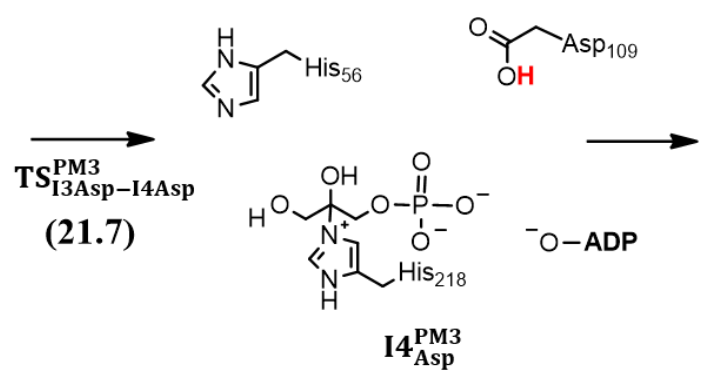

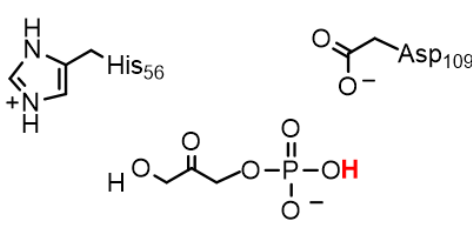

(11.2)

Scheme 4. Schematic representation of the asp-assisted mechanism for the phosphorylation reaction from $\mathrm{I} 2 \mathrm{Asp}_{\mathrm{PM} 3}$ intermediate to products, $\mathrm{P}^{\mathrm{PM} 3}$ in DhaK from $E$. coli obtained at PM3/MM level. Values of the free energy barriers, in $\mathrm{kcal} \cdot \mathrm{mol}^{-1}$, are reported in brackets.

Substrate-assisted mechanism. A 2D-PMF was generated to explore the proton transfer from Dha to ATP and the phosphate transfer from ATP to Dha. Thus, starting from the $\mathrm{I} 2^{\mathrm{PM} 3}$ structure, two anti-symmetric combinations of distances, $\mathrm{d}\left(\mathrm{O} 5_{\mathrm{Dha}}-\mathrm{H} 5_{\mathrm{Dha}}\right)$ $\mathrm{d}\left(\mathrm{OG} 3_{\mathrm{ATP}}-\mathrm{H} 5_{\mathrm{Dha}}\right)$ and $\mathrm{d}\left(\mathrm{PG}_{\mathrm{ATP}}-\mathrm{OB} 3_{\mathrm{ATP}}\right)-\mathrm{d}\left(\mathrm{PG}_{\mathrm{ATP}}-\mathrm{O} 5_{\mathrm{Dha}}\right)$, were used to generate the FES. In the next stage, consisting into the release of the phosphorylated Dha from the protein, the anti-symmetric combination of distances defining the proton transfer back to the His56A, d(O4 $\left.{ }_{\text {Dha }}-\mathrm{HE} 2_{\mathrm{His} 56}\right)-\mathrm{d}\left(\mathrm{NE} 2_{\mathrm{His56}}-\mathrm{HE} 2_{\mathrm{His} 56}\right)$, together with the inter atomic 
distance defining the $\mathrm{C} 1_{\text {Dha }}$ - HE2 $2_{\text {His56 }}$ breaking bond, were used to generate the FES. The resulting FESs computed at PM3/MM level are shown in Figure 3.

a

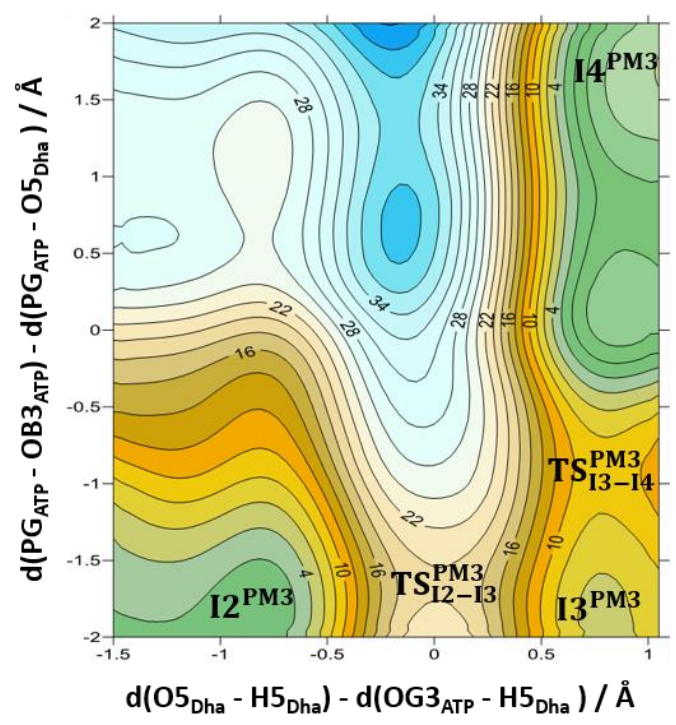

b

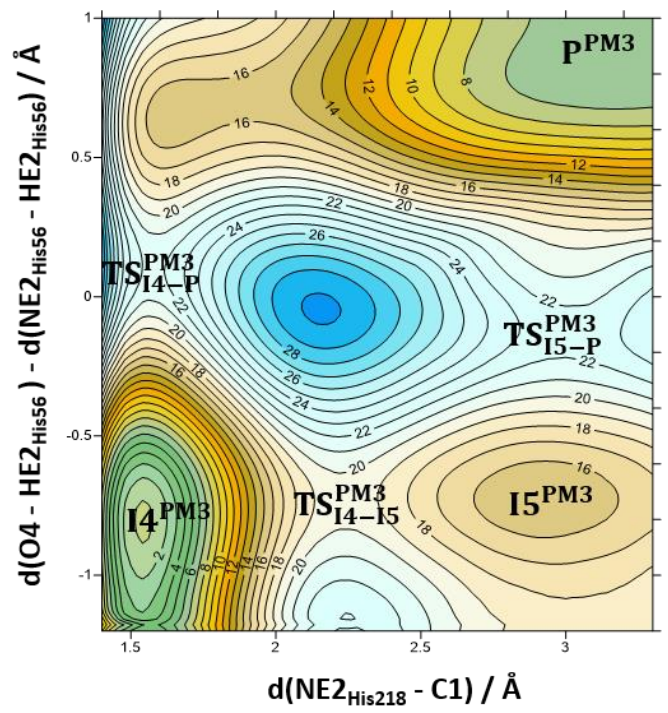

Figure 3. PM3/MM FESs of the substrate-assisted mechanism for the phosphorylation reaction catalyzed by DhaK from E.coli. Proton transfer from Dha to the transferring phosphoryl group of ATP followed by the phosphoryl transfer to Dha (a), releasing of the final products where the proton returns to His56A and it takes place the cleavage of the bond with His218A (b). Values of the isoenergetic lines on the 2D-PMFs are in kcal· mol. ${ }^{-1}$

The first conclusion that can be derived from the analysis of the FESs presented in Figure 3 is that, according to panel a, the activation of the phosphate by the transferring of a proton from Dha to the phosphate of ATP (I2 ${ }^{\mathrm{PM} 3}$ to $\left.\mathrm{I}^{\mathrm{PM} 3}\right)$ does not take place concertedly with the phosphoryl transfer itself ( $\mathrm{I}^{\mathrm{PM} 3}$ to $\left.\mathrm{I} 4^{\mathrm{PM} 3}\right)$. Interestingly, the phosphate transfer step presents free energy barriers significantly lower than the rest of the steps. Indeed, while the rest of the steps have free energy barriers in the range between 19.6 to $21.6 \mathrm{kcal} \cdot \mathrm{mol}^{-1}$, the free energy barrier of the phosphoryl transfer step from the intermediate $\mathrm{I}^{\mathrm{PM} 3}$ is just $3.6 \mathrm{kcal} \cdot \mathrm{mol}^{-1}$. The complete migration of the phosphate group is reached in the $\mathrm{I}^{\mathrm{PM} 3}$ intermediate that appears to be much more stable than the $\mathrm{I}^{\mathrm{PM} 3}$ intermediate and even more stable than the initial $\mathrm{I} 2^{\mathrm{PM} 3}$ intermediate. Key interatomic distances of the transition state structures located on the quadratic regions of the FESs are reported in Table S2 of the Supporting Information. A representative structure of the TS of the phosphoryl transfer step, $\mathrm{I} 3^{\mathrm{PM} 3}$ to $\mathrm{I}^{\mathrm{PM}}{ }^{\mathrm{PM}}$, is 
presented in Figure 4. The $\mathrm{TS}_{\mathrm{I} 3-\mathrm{I} 4}^{\mathrm{PM} 3}$ describes an asynchronous breaking and forming bonds process with the phosphoryl transfer in an early stage of the process. The distances from the transferring phosphorous atom to the donor and acceptor atoms are $1.77 \pm 0.04$ and $2.57 \pm 0.05 \AA$, respectively, with a distance between the donor and acceptor oxygen atoms of $3.98 \pm 0.09 \AA$, and an angle of $\mathrm{OB} 3_{\mathrm{ATP}}-\mathrm{PG}_{\mathrm{ATP}}-\mathrm{O} 5_{\mathrm{Dha}}$ of 134.8 degrees. Hydrogen bond interactions are established in this TS between the oxygen atoms of the phosphate and residues Ser80A, Thr79A and Arg178B, together with interactions with a $\mathrm{Mg}^{2+}$ cations and a C-H bond of Gly78B. The Asp109A, on the contrary, is interacting with the substrate. It should be mentioned that, based on activity measurements on site-directed mutants, Shi et al. ${ }^{34}$ proved that the conserved residues His218A, His56A and Asp109A were important for the catalytic activity of the DhaK, which would be in agreement with the description of $\mathrm{TS}_{\mathrm{I} 3-\mathrm{I} 4}^{\mathrm{PM}}$.

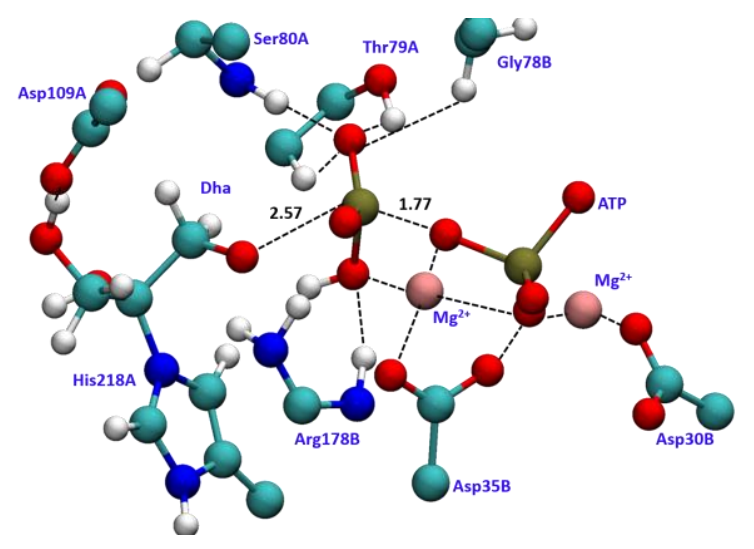

Figure 4. Representative snapshot of the $\mathrm{TS}_{\mathrm{I} 3-\mathrm{I} 4}^{\mathrm{PM} 3}$ structure obtained at $\mathrm{PM} 3 / \mathrm{MM}$ corresponding to the phosphoryl transfer step, $\mathrm{I}^{\mathrm{PM} 3}$ to $\mathrm{I}^{\mathrm{PM} 3}$, in the substrate-assisted mechanism. Dashed lines represent important interactions and distances are reported in $\AA$.

As observed in Figure 3b, the release of the products from the protein can be reached by means of a stepwise mechanism through an intermediate $5^{\mathrm{PM} 3}$ (with free energy barriers of 19.6 and $7.5 \mathrm{kcal} \cdot \mathrm{mol}^{-1}$ ) or in a competitive single step (with a free energy barrier of $21.6 \mathrm{kcal} \cdot \mathrm{mol}^{-1}$ ).

Asp-assisted mechanism. In order to study the first step of this mechanism, and based on the experience achieved from the study of the previous mechanism, a 1D-PMF has been explored using the antisymmetric combination of distances corresponding to the transfer of proton from Dha to Asp109A, d(O5 $\left.5_{D h a}-H 5_{\text {Dha }}\right)-d\left(H 5_{D h a}-O D 2_{A s p 109}\right)$. Next, the 
phosphate is transferred from ATP to Dha which corresponds to the conversion from the intermediate $\mathrm{I} 3_{\mathrm{Asp}}^{\mathrm{PM} 3}$ to the intermediate $\mathrm{I} 4_{\mathrm{Asp}}^{\mathrm{PM} 3}$ in Scheme 4. In this case, a 1D-PMF was performed using the antisymmetric combination $d\left(\mathrm{PG}_{\mathrm{ATP}}-\mathrm{OB} 3_{\mathrm{ATP}}\right)-\mathrm{d}\left(\mathrm{PG}_{\mathrm{ATP}}-\mathrm{O}_{\mathrm{Dha}}\right)$. Any attempt to search for a concerted proton and phosphate transfer process, by means of exploring 2D-FESs, was unsuccessful. After the phosphate transfer, Dha-P dissociates from the enzyme by breaking the hemiaminal bond with His218A and the abstraction of the proton by His56A. This can be considered as the inverse step of the initial step of the reaction mechanism shown in Scheme 2. Therefore, a 2D-PMF was explored to study the release of Dha-P from the enzyme and arriving to the products, $\mathrm{P}_{\mathrm{Asp}}^{\mathrm{PM} 3}$. The employed distinguished reaction coordinates are the distance $\mathrm{d}\left(\mathrm{NE} 2 \mathrm{His}_{\mathrm{H} 28^{-}}\right.$ $\mathrm{C} 1)$ and the anti-symmetric combination $\mathrm{d}\left(\mathrm{NE} 2_{\mathrm{His}}{ }_{6}-\mathrm{HE} 2_{\mathrm{His} 56}\right)-\mathrm{d}\left(\mathrm{O} 4-\mathrm{HE} 2_{\mathrm{His} 56}\right)$. At this point, we must bear in mind that Asp109A is still protonated whereas in the starting structure it was deprotonated. Consequently, a migration of this proton to one of the oxygen atoms of phosphate group of Dha-P $\left(\mathrm{OG} 2_{\mathrm{ATP}}\right)$ has been additionally studied, what is referred in Scheme 4 as the conversion from $\mathrm{P}_{\mathrm{Asp}}^{\mathrm{PM} 3}$ to $\mathrm{P}^{\mathrm{PM} 3}$. Hence, a 1D-PMF was computed using the anti-symmetric combination of distances $\mathrm{d}\left(\mathrm{OD} 2_{\mathrm{Asp} 109}-\mathrm{H} 5_{\mathrm{Dha}}\right)$ $\mathrm{d}\left(\mathrm{H} 5_{\mathrm{Dha}}-\mathrm{OG} 2_{\mathrm{ATP}}\right)$. The corresponding FESs for the full transformation from $\mathrm{I} 2_{\mathrm{Asp}}^{\mathrm{PM} 3}$ to $\mathrm{P}^{\mathrm{PM} 3}$ computed at PM3/MM level are displayed in Figure 5 and the free energy barrier of every step are reported in Scheme 4. 


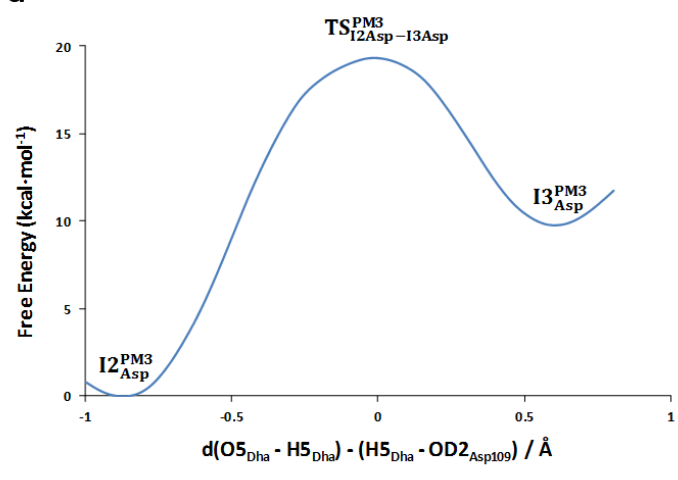

C

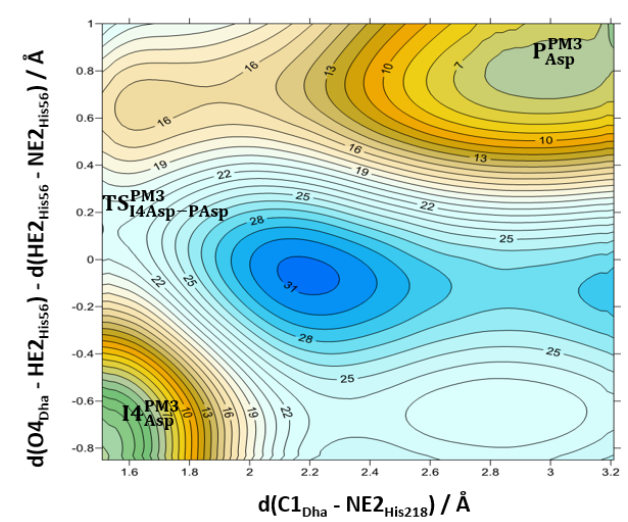

b

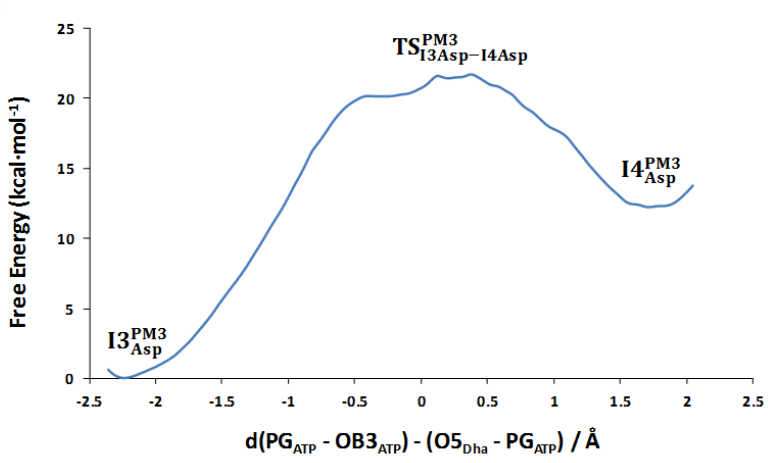

d

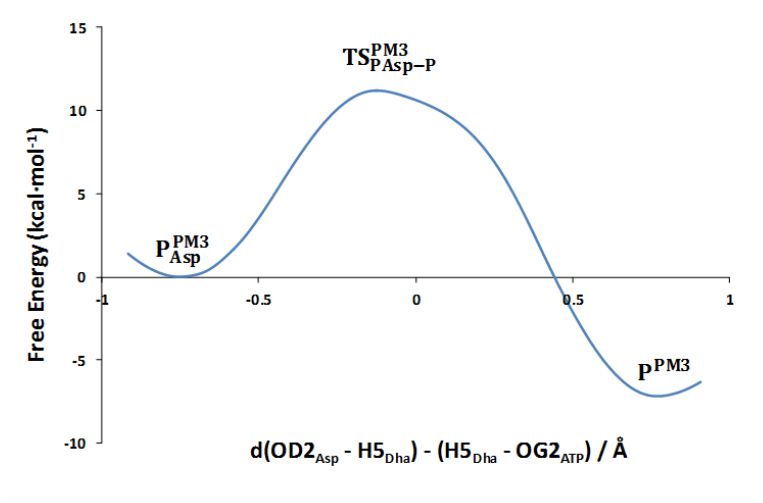

Figure 5. PM3/MM FESs of the chemical steps of the asp-assisted mechanism for the phosphorylation reaction catalyzed by DhaK from E.coli. Values of the isoenergetic lines on the 2D-PMF are in $\mathrm{kcal} \cdot \mathrm{mol}^{-1}$. Proton transfer from Dha to Asp109A (a), phosphoryl transfer from ATP to Dha (b), releasing of the products where the proton returns to His56A and it takes place the cleavage of the bond with His218A (c), proton transfer from Asp109A to ADP, reaching the final products (d).

The analysis of the FESs presented in Figure 5 shows how the phosphoryl transfer step, from I3 ${ }_{\mathrm{Asp}}^{\mathrm{PM} 3}$ to $\mathrm{I}_{\mathrm{Asp}}^{\mathrm{PM} 3}$, presents the highest energy barrier, $21.7 \mathrm{kcal} \cdot \mathrm{mol}^{-1}$. Nevertheless, the transformation from $\mathrm{I} 2{ }_{\mathrm{Asp}}^{\mathrm{PM} 3}$ to $\mathrm{I}_{\mathrm{Asp}}^{\mathrm{PM} 3}$, and especially the transformation from $\mathrm{I} 4_{\mathrm{Asp}}^{\mathrm{PM} 3}$ to $\mathrm{P}_{\mathrm{Asp}}^{\mathrm{PM} 3}$ also take place through similar free energy barriers; 19.4 and $21.5 \mathrm{kcal} \cdot \mathrm{mol}^{-1}$, respectively. A detail of a representative structure of the TS for the phosphoryl transfer step is shown in Figure 6 while key interatomic distances of all transition states are reported in Table S3 of Supporting Information. As in the case of the substrate-assisted mechanism, the transferred phosphate is stabilized in the $\mathrm{TS}_{\mathrm{I} 3 \mathrm{Asp}-\mathrm{I} 4 \mathrm{Asp}}^{\mathrm{PM} 3}$ by hydrogen bond interactions with three residues, Ser80A, Thr79A and Arg178B, and by one of the $\mathrm{Mg}^{2+}$ cations located in the active site. Gly78B also interacts with the transferring 
phosphate, although by a weaker $\mathrm{C}-\mathrm{H} \cdots \mathrm{O}$ interaction. The protonated Asp109A is interacting with Dha but, as in the previous mechanism, with the hydroxyl group. According to the distances established between the phosphor atom with the donor and acceptor oxygen atoms $(2.32 \pm 0.06$ and $1.98 \pm 0.06 \AA$, respectively), we would be describing this process as a concerted asynchronous phosphoryl transfer but, in contrast to the substrate-assisted mechanism, the TS would be in an advance stage of the reaction. The distance between the donor and acceptor oxygen atoms $(4.07 \pm 0.11 \AA)$ and the $\mathrm{OB} 3_{\mathrm{ATP}}-\mathrm{PG}_{\mathrm{ATP}}-\mathrm{O} 5_{\mathrm{Dha}}$ angle on the $\mathrm{TS}_{\mathrm{I} 3 \mathrm{Asp}-\mathrm{I} 4 \mathrm{Asp}}^{\mathrm{PM} 3}$ (158.7 degrees) are similar to the values obtained in the TS of the phosphoryl transfer step obtained in the substrateassisted mechanism, within the statistical uncertainty.

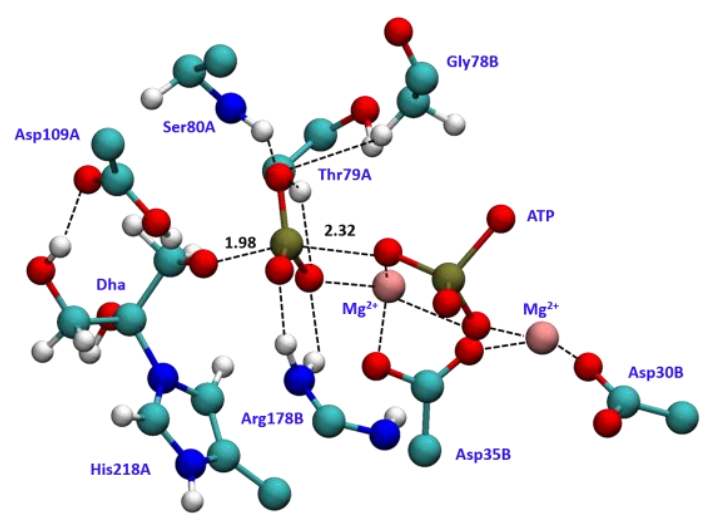

Figure 6. Representative snapshot of the $\mathrm{TS}_{\mathrm{I} 3 \mathrm{Asp}-\mathrm{I} 4 \mathrm{Asp}}^{\mathrm{PM}}$ obtained at PM3/MM level corresponding to the phosphoryl transfer step, $\mathrm{I} 3{ }_{\mathrm{Asp}}^{\mathrm{PM} 3}$ to $\mathrm{I} 4_{\mathrm{Asp}}^{\mathrm{PM} 3}$, in the asp-assisted mechanism. Dashed lines indicate important interactions and key distances are reported in $\AA$.

In addition to the exploration of the two mechanisms, a reaction path from $\mathrm{I} 4 \mathrm{Asp}_{\mathrm{PM}}^{\mathrm{PM}}$ to $\mathrm{I}^{\mathrm{PM} 3}$ has been traced by computing a 1D-PMF using the antisymmetric combination of the bond-breaking and bond-forming distances describing the proton transfer from Asp109A to one of the negatively charged phosphate oxygen atoms of Dha-P: $\mathrm{d}\left(\mathrm{OD} 2_{\mathrm{Asp} 109}-\mathrm{H} 5_{\mathrm{Dha}}\right)-\mathrm{d}\left(\mathrm{H} 5_{\mathrm{Dha}}-\mathrm{OG} 2_{\mathrm{ATP}}\right)$. The resulting free energy profile, presented in Figure 7 , reveals that the $\mathrm{I}^{\mathrm{PM} 3}$ intermediate located when exploring the substrateassisted mechanism is significantly more stable than the $\mathrm{I} 4_{\mathrm{Asp}}^{\mathrm{PM} 3}$. This, together with the comparison of the energy barriers for each step, supports the proposal of the substrateassisted mechanism as being more favourable than the asp-assisted mechanism. Key interatomic distances of the located transition state are reported in Table S4 of Supporting Information. 


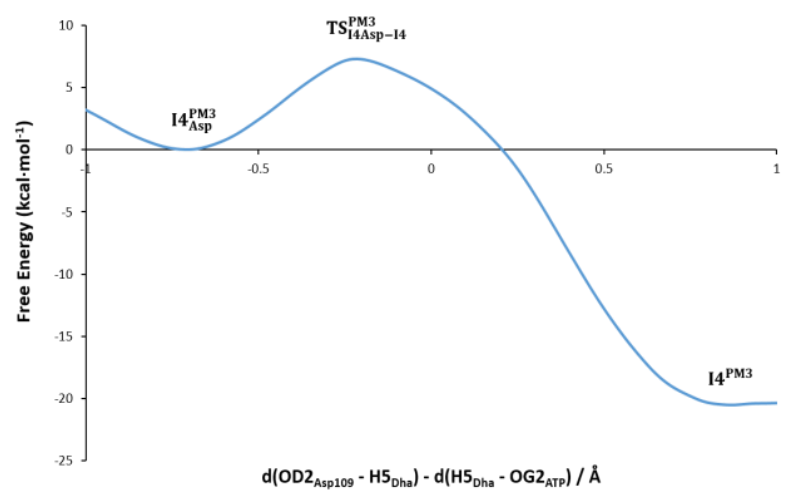

Figure 7. PM3/MM 1D-PMF corresponding to the transition from $4_{A s p}^{\mathrm{PM} 3}$ to $\mathrm{I} 4^{\mathrm{PM} 3}$.

In order to analyse the impact of the positively charged Arg178B, additional PM3/MM PESs of the most relevant chemical step, from intermediate I 2 to intermediate I4, have been computed in both mechanisms by including this residue in the QM sub-set of atoms. $\operatorname{Arg} 178 \mathrm{~B}$ is interacting with the terminal phosphate oxygen and could preferentially favour the asp-assisted mechanism by stabilizing the O- group in Dha and the $\gamma$-phosphate from ATP. A schematic representation of the active site including the residue Arg178B in the QM part, and the obtained PESs are depicted in Figure S11, S12 and S13 of Supporting Information. The resulting PESs show that the inclusion of this residue in the QM region produces a decrease in the energy barrier of the proton transfer from Dha to Asp109A in the asp-assisted mechanism but this decrease is not large enough to change the trend obtained with the smaller QM region. Comparing the potential energy barriers of the two mechanism (see Supporting Information) shows that the substrate-assisted mechanism (with potential energy barriers of 22 and $10 \mathrm{kcal} \cdot \mathrm{mol}^{-}$ ${ }^{1}$ ) is still more favourable that for the asp-assisted mechanism (with potential energy barriers of 25 and $18 \mathrm{kcal} \cdot \mathrm{mol}^{-1}$ ).

\section{B3LYP:PM3/MM FESs of the phosphorylation reaction.}

According to the PM3/MM FESs, it appears that the substrate-assisted mechanism would be kinetically more favourable than the asp-assisted mechanism. Then, the correction of the PM3/MM FESs at B3LYP:PM3/MM level has been focused just on the former. The resulting surfaces are presented in Figure 8 while a schematic representation of the mechanism obtained at this level of theory is shown in Scheme 5. 
The comparison between these and the previous FESs shown in Figure 3 render interesting conclusions. The first observation is that the B3LYP:PM3/MM results describe the first two steps in the reverse order than the PM3/MM calculations; first, the phosphoryl transfer would take place ( $12^{\mathrm{DFT}: \mathrm{PM} 3}$ to $\mathrm{I}^{\mathrm{DFT}: \mathrm{PM} 3}$ ) and later the proton from Dha would be transferred to the phosphate group (I3 ${ }^{\text {DFT:PM3 }}$ to $\mathrm{I}^{\mathrm{DFT}: \mathrm{PM} 3}$ ). The intermediate $\mathrm{I} 3^{\mathrm{DFT}: \mathrm{PM} 3}$ corresponds to structures where the phosphate is already transferred to the Dha, in contrast to the $\mathrm{I}^{\mathrm{PM} 3}$. Nevertheless, the distance between the phosphor atom of the transferring phosphate group $\left(\mathrm{PG}_{\mathrm{ATP}}\right)$ and the $\mathrm{O} 5_{\mathrm{Dha}}$ is noticeable larger $\left(1.87 \AA\right.$ ) than the final distance measured in, for instance, I4 ${ }^{\text {DFT:PM3 }}$ (1.67 $\AA$ ).

Another important effect of correcting the PM3/MM FESs is, as observed when comparing Figure $3 b$ with Figure $8 b$, that the reaction coordinate of the $\mathrm{TS}_{\mathrm{I} 4-\mathrm{P}}^{\mathrm{DFT} P \mathrm{PM} 3}$ appears to be displaced to values significantly closer to $\mathrm{P}^{\mathrm{DFT}: \mathrm{PM} 3}$ than in the previous $\mathrm{TS}_{\mathrm{I} 4-\mathrm{P}}^{\mathrm{PM}}$. This is valid not only with regard to the proton transfer but also the breaking bond between the Dha and His218A. The transformation from $\mathrm{I}^{\mathrm{DFT}: \mathrm{PM} 3}$ to $\mathrm{P}^{\mathrm{DFT}: \mathrm{PM} 3}$ through the intermediate $5^{\mathrm{DFT}: \mathrm{PM} 3}$ is only slightly different to the description we obtained from the PM3/MM FES (Figure 3b), but with a first TS, $\mathrm{TS}_{\mathrm{I} 4-\mathrm{I} 5}^{\mathrm{DFT}}$, appearing in a more advance stage of the $\mathrm{NE} 2_{\mathrm{His} 218}-\mathrm{C} 1_{\text {Dha }}$ breaking bond. Interestingly, different reaction paths computed for the counterpart reaction in solution were also obtained when the QM atoms were described at semiempirical or DFT levels, in our previous QM/MM study of the phosphoryl transfer reaction in solution. ${ }^{43}$

Regarding the free energy barriers, it is unavoidable to stress the dramatic variations of for the phosphoryl transfer step when comparing the PM3/MM with the B3LYP:PM3/MM FESs. While free energy barriers of $19.9 \mathrm{kcal} \cdot \mathrm{mol}^{-1}$ and $3.6 \mathrm{kcal} \cdot \mathrm{mol}^{-}$ ${ }^{1}$ were obtained for the transformation from ${ }_{2} 2^{\mathrm{PM} 3}$ to $\mathrm{I}^{\mathrm{PM} 3}$ and from $\mathrm{I} 3^{\mathrm{PM} 3}$ to $\mathrm{I} 4^{\mathrm{PM} 3}$, respectively, the free energy barriers when the surfaces are corrected at DFT level are 44.3 and $53.6 \mathrm{kcal} \cdot \mathrm{mol}^{-1}$, for the transformation from I2 ${ }^{\text {DFT:PM3 }}$ to $\mathrm{I}^{\mathrm{DFT}: \mathrm{PM} 3}$ and from I3 DFT:PM3 to I4 ${ }^{\mathrm{DFT}: \mathrm{PM} 3}$, respectively. This effect can be derived from the fact that the PM3/MM sampling does not properly cover and explore the representative structures of the B3LYP/MM space. As observed in Scheme 5, the DFT:PM3/MM corrections for the release of the phosphorylated Dha, the transformation from $\mathrm{I}^{\text {DFT:PM3 }}$ to $\mathrm{P}^{\mathrm{DFT}: \mathrm{PM} 3}$, render free energy barriers that are now significantly lower than the original values obtained at PM3/MM level (see Scheme 3). It appears that there are significant biases from the low-level methods indicating a not marginal contribution of degrees of 
freedom other than the ones employed in the distinguished reaction coordinate. Then, in order to check the reliability of the correction scheme for this reaction, the next step in our study was to compute PESs at B3LYP/MM level.

a

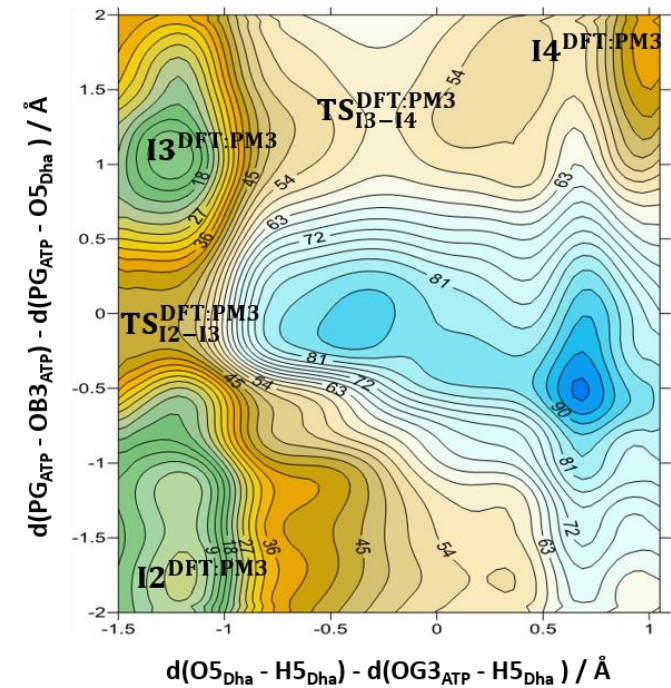

b

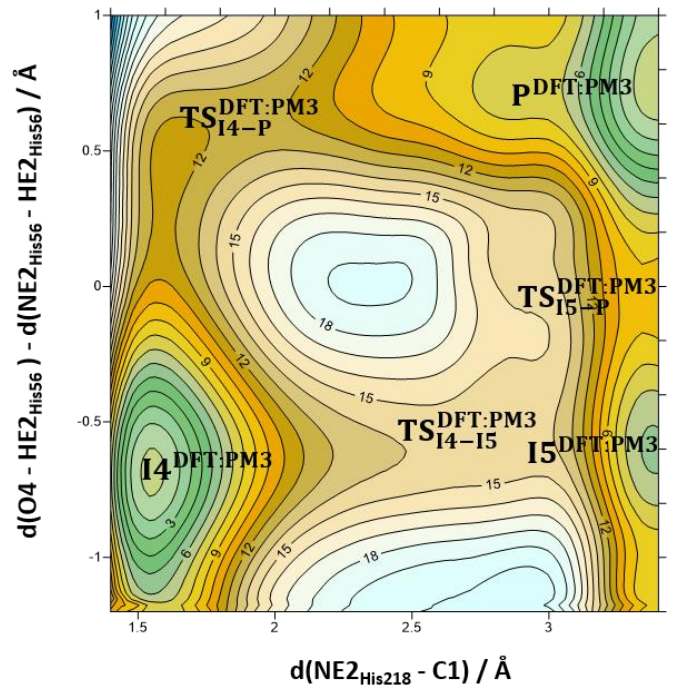

Figure 8. B3LYP:PM3/MM FESs of the substrate-assisted phosphoryl transfer reaction from ATP to Dha catalyzed by DhaK from E.coli. Values of the isoenergetic lines are in $\mathrm{kcal} \cdot \mathrm{mol}^{-1}$. Phosphoryl transfer from ATP to Dha followed by the proton transfer from Dha to the transferred phosphoryl group (a), releasing of the final products where the proton returns to His56A and it takes place the cleavage of the bond with His218A (b). 

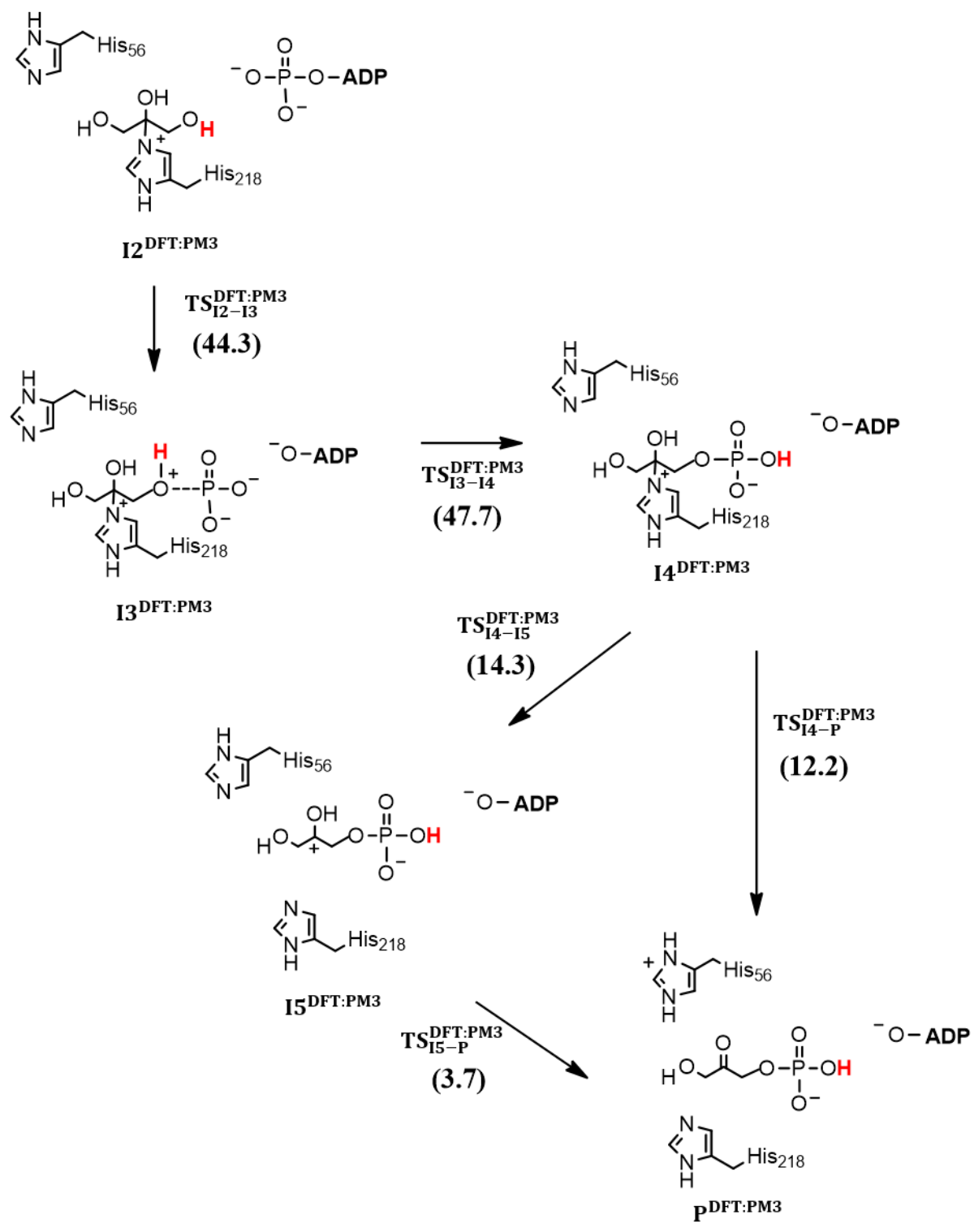

Scheme 5. Schematic representation of the substrate-assisted mechanism for the phosphorylation reaction from $\mathrm{I}^{\mathrm{DFT}: \mathrm{PM} 3}$ intermediate to products, $\mathrm{P}^{\mathrm{DFT}: \mathrm{PM} 3}$, in DhaK from E. coli obtained at DFT:PM3/MM level. Values of free energy barriers, in $\mathrm{kcal} \cdot \mathrm{mol}^{-1}$, are reported in brackets.

\section{B3LYP/MM Potential Energy Surfaces.}

The B3LYP/MM PESs, deposited as Figures S6 and S7 of the Supporting Information, were used to explore the reaction mechanism and to select initial structures to be refined as TS structures. The nature of the located and characterized TSs were confirmed by computing the Hessian for the QM subset of atom in the presence of the protein and solvent. Then, intrinsic reaction paths (IRCs) were traced down to the reactants and 
products valleys to confirm the obtained mechanism. The schematic representation of the mechanisms that are deduced from the B3LYP/MM PESs are shown in Scheme 6, the potential energy profiles are shown in Figure 9, and the TSs of the phosphoryl transfer step of the substrate-assisted and asp-assisted mechanisms are reported in Figures 10 and 11.

a

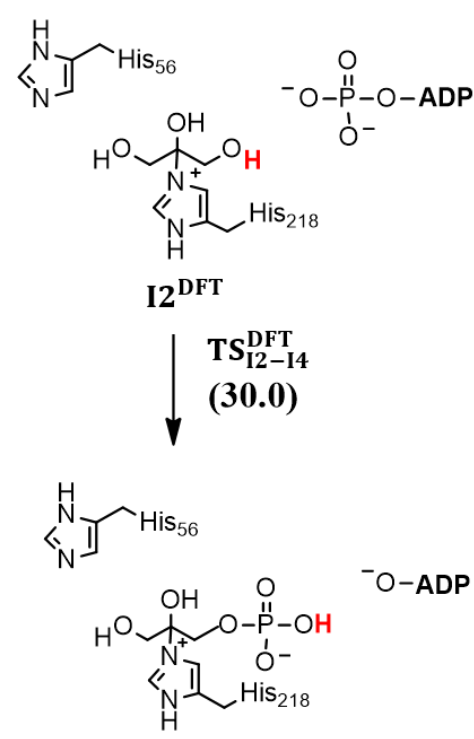
$14^{\mathrm{DFT}}$

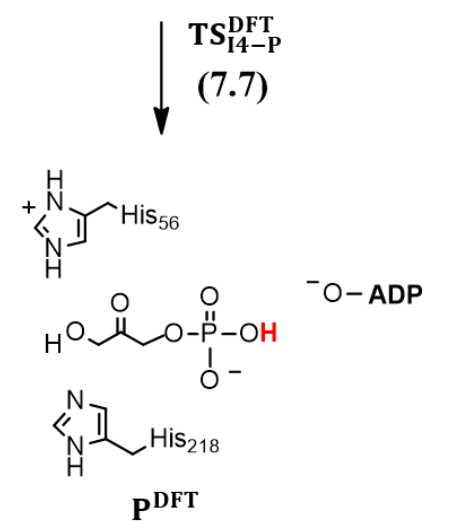

b
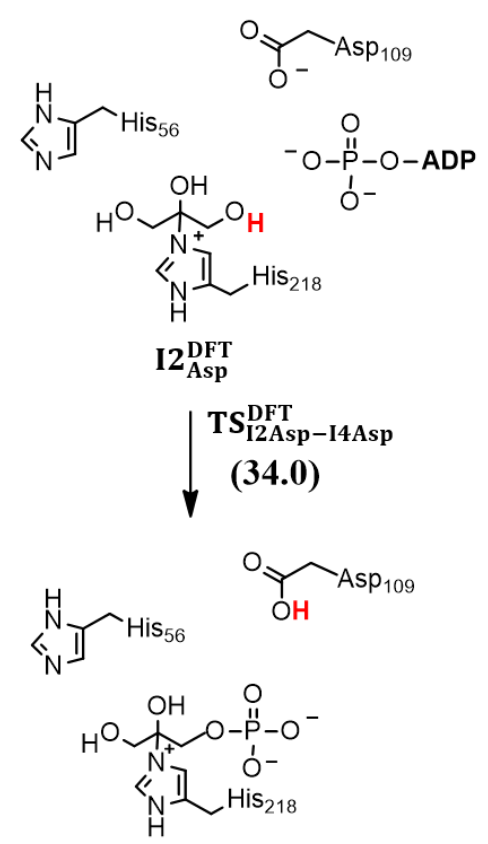

I4 Asp

Scheme 6. Schematic representation of the substrate-assisted (a) and asp-assisted (b) mechanisms for the phosphorylation reaction from ATP to Dha in DhaK from E.coli deduced from PESs computed at B3LYP/MM level. Values of potential energy barriers, in $\mathrm{kcal} \cdot \mathrm{mol}^{-1}$, are reported in brackets. 

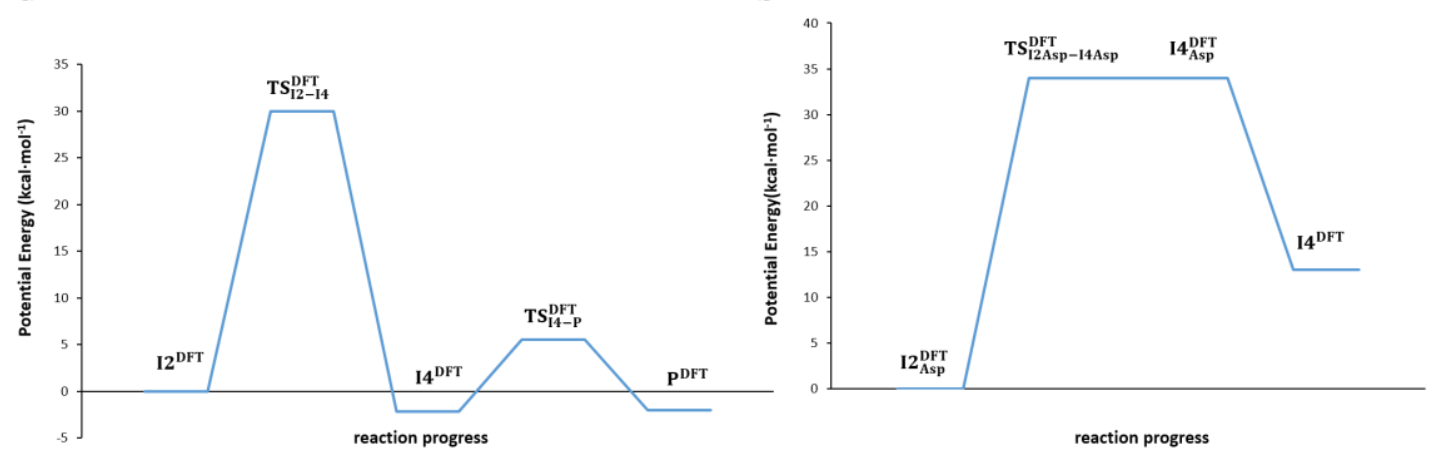

Figure 9. B3LYP /MM potential energy profile of the substrate-assisted (a) and aspassisted (b) phosphoryl transfer reaction mechanisms from ATP to Dha catalyzed by DhaK from E.coli.

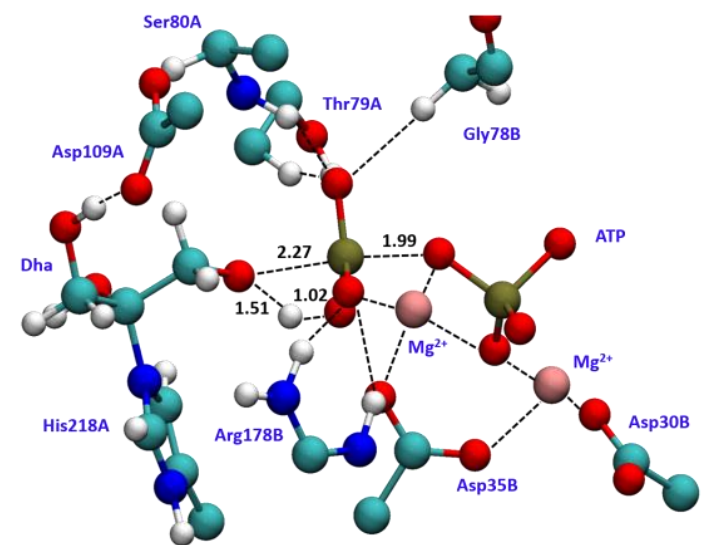

Figure 10. Transition State structure located at B3LYP/MM level, $\mathrm{TS}_{12-I 4}^{\mathrm{DFT}}$, corresponding to the phosphoryl transfer step, $\mathrm{I}^{\mathrm{DFT}}$ to $\mathrm{I}^{\mathrm{DFT}}$, in the substrate-assisted mechanism. Dashed lines represent important interactions while key distances are reported in $\AA$.

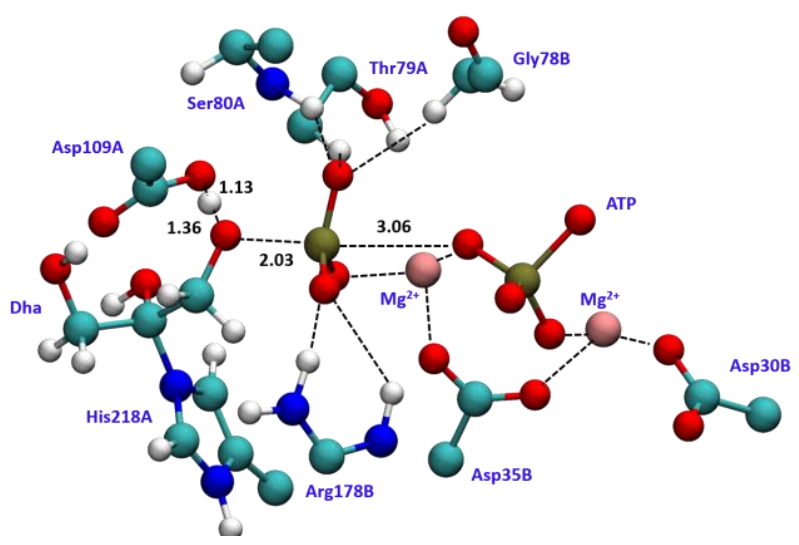


Figure 11. Transition State structure located at B3LYP/MM level, TS $\mathrm{I}_{\text {I2Asp-I4Asp }}^{\mathrm{DFT}}$, corresponding to the phosphoryl transfer step, I2 $\mathrm{AFp}$ to $\mathrm{I} 4_{\mathrm{Asp}}^{\mathrm{DFT}}$, in the asp-assisted mechanism. Dashed lines represent important interactions while key distances are reported in $\AA$.

The located TSs and their corresponding IRCs confirm that, in both mechanisms, the transformation from $\mathrm{I} 2^{\mathrm{DFT}}$ to $\mathrm{I} 4^{\mathrm{DFT}}$ takes place in a single step, in contrast to the PM3/MM or the DFT:PM3/MM calculations that describe the process through an intermediate I3 (see Scheme 3, 4 and 5). Nevertheless, the comparison of Figure 4 and 6 with Figure 10 and 11 shows that the TSs of the phosphoryl transfer at DFT/MM level are not so different from the average TS structures located at PM3/MM level. Thus, the $\mathrm{TS}_{\mathrm{I} 2-\mathrm{I} 4}^{\mathrm{DFT}}$ located for the substrate-assisted mechanism is also describing an asynchronous but concerted process with the phosphoryl transfer in an early stage of the process: the distances from the transferring phosphorous atom to the donor and acceptor atoms are 1.99 and $2.27 \AA$, respectively. And regarding the asp-assisted mechanism, the $\mathrm{TS}_{\text {I2Asp-I4Asp }}^{\mathrm{DFT}}$ is also resembling the TS located at PM3/MM level, $\mathrm{TS}_{\mathrm{I} 3 \mathrm{Asp}-\mathrm{I} 4 \mathrm{Asp}}^{\mathrm{PM}}$. The distances from the transferring phosphorous atom to the donor and acceptor atoms of 3.06 and $2.03 \AA$, respectively, again describe an asynchronous phosphoryl transfer step where the phosphoryl is in an advance stage of the reaction. A difference is detected with regard to the proton transfer from the Dha to the ATP or the Asp109A, depending on the mechanism. As can be deduced from Figure 10 and 11, the DFT/MM calculations render TSs where the proton is not completely transferred to the acceptor atom, while in the TS structures derived from the PM3/MM calculations the proton was. The angle of $\mathrm{OB} 3_{\mathrm{ATP}}-\mathrm{PG}_{\mathrm{ATP}}-\mathrm{O} 5_{\mathrm{Dha}}$ measured in $\mathrm{TS}_{\mathrm{I} 2-\mathrm{I} 4}^{\mathrm{DFT}}$ and $\mathrm{TS}_{\mathrm{I} 2 \mathrm{Asp}-\mathrm{I} 4 \mathrm{Asp}}^{\mathrm{DFT}}$ is 149.1 and 167.2 degrees, respectively, which do not correspond neither to a perfect alignment of the three atoms but significantly more linear than in the structures deduced from the TSs obtained at PM3/MM level. The distances between the donor and acceptor oxygen atoms, $\mathrm{O} 5_{\mathrm{Dha}}-\mathrm{OB} 3_{\mathrm{ATP}}$, is $4.10 \AA$ for the substrate-assisted mechanism, very close to the values deduced at PM3/MM level, but significantly larger, $5.05 \AA$ in the case of aspassisted mechanism. Structural analysis of both TSs are also supporting the role of key residues such as $\operatorname{Arg} 178 \mathrm{~B}, \mathrm{Ser} 80 \mathrm{~A}$ and Gly78B, together with the $\mathrm{Mg}^{2+}$ cation of the active site. According to the interatomic distances, an interaction is detected between the transferring phosphate and Thr79A but, again, it would correspond to a weak interaction. A table listing the values of the inter-atomic distances in the TSs are 
reported in Table S5 of the Supporting Information. From the energetic point of view, as observed in Figure 9, the barriers that can be deduced from the B3LYP/MM PESs further support the substrate-assisted mechanism by comparison with the asp-assisted mechanism: 30 and $34 \mathrm{kcal} \cdot \mathrm{mol}^{-1}$, respectively. In addition, a very exothermic (ca. -25 $\mathrm{kcal} \cdot \mathrm{mol}^{-1}$ ) and barrier-less profile was obtained when trying to connect $\mathrm{I} 4_{\mathrm{Asp}}^{\mathrm{DFT}}$ with I $4^{\mathrm{DFT}}$ indicating a much more favourable product when the reaction proceeds by means of the substrate-assisted mechanism, in agreement with the PM3/MM free energy profile presented in Figure 7. The exploration of the reaction in terms of FESs at DFT level is prohibitive at present, but considering the previous results, smaller values of the free energy barriers would be expected if statistical simulations were carried out. Finally, according to the DFT/MM results, the conversion from $14^{\mathrm{DFT}}$ into products would be feasible in a thermo-neutral single step (reaction energy equal to $0.2 \mathrm{kcal} \cdot \mathrm{mol}^{-}$ ${ }^{1}$ ) with a low energy barrier of $7.7 \mathrm{kcal} \cdot \mathrm{mol}^{-1}$ (see Scheme 6).

\section{CONCLUSIONS}

An exhaustive theoretical study of the phosphoryl transfer reaction from ATP to Dha catalyzed by DhaK from E. coli is reported in the present paper. Two mechanisms have been explored according to previous proposals published in the literature for related phosphate transfer reactions. The study has been carried out at three different levels: first calculations of FESs at PM3/MM level; second the semiempirical QM description of the FESs has been improved at DFT level by means of spline corrections; and finally the reaction mechanisms have been explored based on B3LYP/MM PESs. The two explored mechanisms basically differ on the species involved on the activation of the $\mathrm{O} 5$ atom of Dha. Thus, in the substrate-assisted mechanism, the proton from Dha is directly transferred to the ATP while in the asp-assisted mechanism, Asp109A abstracts the proton from Dha and generates an oxyanion suitable for the attack of the ATP $\gamma$ phosphorus atom. Our results suggest that, regardless of the level of theory employed in the calculations, the former would be kinetically more favourable than the later. This conclusion, in agreement with the computational studies of De Vivo et al. for the phosphoryl transfer catalyzed by CDK $2,{ }^{25}$ and the early studies on cAMP-PKA by Hart et al., ${ }^{27}$ is also supported by the fact that the intermediate located when exploring the substrate-assisted mechanism appears to be significantly more stable than the one obtained when studied the asp-assisted mechanism. Our calculations show that after the 
binding of Dha to the enzyme through a hemiaminal bond with His218A, the phosphate is transferred from ATP to Dha, acting Asp109A not as a base but likely having an important structural role by posing the Dha and other residues of the active site in the proper orientation to stabilize the TS. The Dha would transfer the proton directly to one of the oxygen atoms of the transferring phosphate. Then, a reduction of the activity of the enzyme after mutation of residue Asp $109 \mathrm{~A}^{34}$ can not unequivocally demonstrate its role as a base but it can be also indicating an important structural role in the reaction, as we are proposing based on the analysis of the TSs. Thus, considering that Asp109A is not involved in forming or breaking covalent bonds during the substrate-assisted mechanism, we suggest that measurements of $\mathrm{O}^{18}$ KIEs on the oxygen atoms of Asp109A could report valuable information on the reaction mechanism.

It is important to stress that significant different mechanistic details and energetics are deduced from the different computational methods. Nevertheless, the structures of the TSs corresponding to the phosphate transfer at DFT/MM level significantly resemble the ones obtained at PM3/MM level although subtle nuances can be identified. The TSs suggest that residues such as Gly78B, Thr79A, Ser80A, Arg178B and one of the $\mathrm{Mg}^{2+}$ cations of the active site would be stabilizing the transferred phosphate. His218A and His56A would have a decisive role in the preceding chemical steps. This analysis of the role of the key residues of the active site would be partly supported by the kinetic studies of Shi et al. ${ }^{34}$, based on activity measurements on site-directed mutants, that indicated the importance of the conserved residues His218A, His56A and Asp109A for the catalytic activity of DhaK.

If kinetics come into focus, dramatic differences are obtained depending on the computational method. Thus, the study based on PM3/MM FESs suggests that the rate limiting step of the substrate-assisted mechanism corresponds to the release of the substrate with a free energy barrier of $21.6 \mathrm{kcal} \cdot \mathrm{mol}^{-1}$, while the phosphor transfer step presents a free energy barrier of $3.6 \mathrm{kcal} \cdot \mathrm{mol}^{-1}$. When the FESs are corrected at B3LYP:PM3/MM level, the free energy barrier for the release of the phosphorylated Dha is decreased to $12.2 \mathrm{kcal} \cdot \mathrm{mol}^{-1}$ while the phosphoryl transfer step becomes the rate limiting step with a barrier of $47.7 \mathrm{kcal} \cdot \mathrm{mol}^{-1}$. This dramatic effect can be derived from the limitations of the semiempirical PM3 Hamiltonian that, despite providing reasonable structures for the phosphoryl transfer TSs, the sampling obtained at this level does not properly cover and explore all the representative structures of the B3LYP/MM space. 
Consequently, the spline corrections technique applied to the PM3/MM FESs can not provide a complete picture of all possible single molecule reaction paths. Nonetheless, the potential energy barriers of the phosphoryl transfer step (coupled to the proton transfer from Dha to the ATP or to the Asp109A) deduced from the B3LYP/MM PESs, which is the rate limiting step, are 30.0 and $34.0 \mathrm{kcal} \cdot \mathrm{mol}^{-1}$ for the substrate-assisted and asp-assisted mechanisms, respectively, thus supporting the former mechanism as the kinetically favoured reaction path. This potential energy barriers appear to be overestimated by comparison with the free energy barrier that can be deduced from experimental rate constants. ${ }^{34,36}$ Nevertheless, considering the impact of introducing statistical simulations (when going from the PM3/MM PES to the PM3/MM FESs), an effect on the barrier could also be expected if calculation of PMFs were feasible at DFT/MM level by exploring a huge number of possible different conformations. Finally, since some of the steps of the process involve the transfer of a light particle, the inclusion of quantum tunnelling effects could slightly lower the effective energy barriers. However, a dramatic effect is not expected and, in any case, similar in both mechanism that would not change the observed trend.

\section{SUPPORTING INFORMATION}

The Supporting Information is available free of charge on the ACS Publications website at DOI:

Time evolution of the RMSD of the backbone atoms of the full enzyme and of the residues of the active site along the equilibration MD simulation of the system; time evolution of the distances between ATP and the $\mathrm{Mg}^{2+}$ ions, and between His56A and Asp109A with the Dha during the equilibration MD simulations; PESs for all the explored steps at PM3/MM and B3LYP/MM level; PESs from I2 to I4 for both studied mechanisms including the Arg178B residue in the QM part and potential energy profiles from I 2 to I4 for both studied mechanisms including the Arg178B residue in the QM part; key interatomic distances for all the located TSs; and Cartesian coordinates of the QM atoms of the TS corresponding to the phosphoryl transfer located at PM3/MM and B3LYP/MM level.

\section{ACKNOWLEDGEMENTS.}

This work was supported by the Spanish Ministerio de Economía y Competitividad (project CTQ2015-66223-C2), Universitat Jaume I (project P1•1B2014-26), Generalitat 
Valenciana (PROMETEOII/2014/022). V.M. is grateful to the University of Bath for the award of a David Parkin Visiting Professorship. Authors acknowledge computational resources from the Servei d'Informàtica of Universitat Jaume I. 


\section{REFERENCES}

(1) Hengge, A. C. In Encyclopedia of Life Sciences; John Wiley \& Sons, London, 2004.

(2) Margutti, S.; Laufer, S. A. ChemMedChem 2007, 2, 1116-1140.

(3) Smith, G. K.; Ke, Z.; Guo, H.; Hengge, A. C. J. Phys. Chem. B 2011, 115, 1371313722 .

(4) Kamerlin, S. C. L.; Williams, N. H.; Warshel, A. J. Org. Chem. 2008, 73, 69606969.

(5) Lassila, J. K.; Zalatan, J. G.; Herschlag, D. Annu. Rev. Biochem. 2011, 80, 669-702.

(6) Ptacek, J.; Snyder, M. Trends Genet. 2006, 22, 545-554.

(7) Zhang, J.; Yang, P. L.; Gray, N. S. Nat. Rev. Cancer 2009, 9, 28-39.

(8) Colinge, J.; César-Razquin, A.; Huber, K.; Breitwieser, F. P.; Májek, P.; SupertiFurga, G. J. Proteomics 2014, 107, 113-127.

(9) Weinmann, H.; Metternich, R. ChemBioChem 2005, 6, 455-459.

(10) Bamborough, P. Expert Opin. Drug Discovery 2012, 7, 1053-1070.

(11) Kamerlin, S. C. L. J. Org. Chem. 2011, 76, 9228-9238.

(12) Wymore, T.; Field, M. J.; Langan, P.; Smith, J. C.; Parks, J. M. J. Phys. Chem. B 2014, 118, 4479-4489.

(13) Marcos, E.; Crehuet, R.; Anglada, J. M. J. Chem. Theory Comput. 2008, 4, 49-63.

(14) Cleland, W. W.; Hengge, A. C. Chem. Rev. 2006, 106, 3252-3278.

(15) Kamerlin, S. C. L.; Florian, J.; Warshel, A. ChemPhysChem 2008, 9, 1767-1773.

(16) López-Canut, V.; Roca, M.; Bertran, J.; Moliner, V.; Tuñón, I. J. Am. Chem. Soc. 2010, 132, 6955-6963.

(17) Akola, J.; Jones, R. O. J. Phys. Chem. B 2003, 107, 11774-11783.

(18) Akola, J.; Jones, R. O. J. Phys. Chem. B 2006, 110, 8121-8129.

(19) Harrison, C. B.; Schulten, K. J. Chem. Theory Comput. 2012, 8, 2328-2335.

(20) Yang, Y.; Cui, Q. J. Phys. Chem. A 2009, 113, 12439-12446.

(21) Lu, X. Y.; Ovchinnikov, V.; Demapan, D.; Roston, D.; Cui, Q. Biochemistry 2017, $56,1482-1497$.

(22) Kiani, F. A.; Fischer, S. Proc. Natl. Acad. Sci. U. S. A. 2014, 111, E2947-E2956.

(23) Aqvist, J.; Kamerlin, S. C. L. Biochemistry 2015, 54, 546-556.

(24) Aqvist, J.; Kamerlin, S. C. L. ACS Catal. 2016, 6, 1737-1743.

(25) De Vivo, M.; Cavalli, A.; Carloni, P.; Recanatini, M. Chem. - Eur. J. 2007, 13, 8437-8444.

(26) Ojeda-May, P.; Li, Y.; Ovchinnikov, V.; Nam, K. J. Am. Chem. Soc. 2015, 137, 12454-12457.

(27) Hart, J. C.; Sheppard, D. W.; Hillier, I. H.; Burton, N. A. Chem. Commun. 1999, 79-80.

(28) Pérez-Gallegos, A.; García-Viloca, M.; González-Lafont, A.; Lluch, J. M. ACS Catal. 2015, 5, 4897-4912.

(29) Pérez-Gallegos, A.; García-Viloca, M.; González-Lafont, A.; Lluch, J. M. Phys. Chem. Chem. Phys. 2015, 17, 3497-3511.

(30) Diaz, N.; Field, M. J. J. Am. Chem. Soc. 2004, 126, 529-542.

(31) Cheng, Y. H.; Zhang, Y. K.; McCammon, J. A. J. Am. Chem. Soc. 2005, 127, 1553-1562.

(32) Jacobsen, D. M.; Bao, Z.-Q.; O'Brien, P.; Brooks, C. L., III; Young, M. A. J. Am. Chem. Soc. 2012, 134, 15357-15370.

(33) Bastidas, A. C.; Deal, M. S.; Steichen, J. M.; Guo, Y.; Wu, J.; Taylor, S. S. J. Am. Chem. Soc. 2013, 135, 4788-4798.

(34) Shi, R.; McDonald, L.; Cui, Q.; Matte, A.; Cygler, M.; Ekiel, I. Proc. Natl. Acad. Sci. U. S. A. 2011, 108, 1302-1307. 
(35) Lopata, A.; Jambrina, P. G.; Sharma, P. K.; Brooks, B. R.; Toth, J.; Vertessy, B. G.; Rosta, E. ACS Catal. 2015, 5, 3225-3237.

(36) García-Alles, L. F.; Siebolo, C.; Nyffeler, T. L.; Flukiger-Bruhwiler, K.; Schneider, P.; Burgi, H. B.; Baumann, U.; Erni, B. Biochemistry 2004, 43, 13037-13045.

(37) Bachler, C.; Flukiger-Bruhwiler, K.; Schneider, P.; Bahler, P.; Erni, B. J. Biol. Chem. 2005, 280, 18321-18325.

(38) Zurbriggen, A.; Jeckelmann, J.-M.; Christen, S.; Bieniossek, C.; Baumann, U.; Erni, B. J. Biol. Chem. 2008, 283, 35789-35796.

(39) Enders, D.; Voith, M.; Lenzen, A. Angew. Chem., Int. Ed. 2005, 44, 1304-1325.

(40) Sánchez-Moreno, I.; Bordes, I.; Castillo, R.; Ruiz-Pernía, J. J.; Moliner, V.; GarcíaJunceda, E. Int. J. Mol. Sci. 2015, 16, 26073.

(41) Shi, R.; McDonald, L.; Cygler, M.; Ekiel, I. Struct. 2014, 22, 478-487.

(42) Saier Jr., M. H. J. Mol. Microbiol. Biotechnol. 2015, 25, 73-78.

(43) Bordes, I.; Ruiz-Pernía, J. J.; Castillo, R.; Moliner, V. Org. Biomol. Chem. 2015, 13, 10179-10190.

(44) Schaftenaar, G.; Noordik, J. H. J. Comput. -Aided Mol. Des. 2000, 14, 123-134.

(45) Li, H.; Robertson, A. D.; Jensen, J. H. Proteins: Struct., Funct., Bioinf. 2005, 61, 704-721.

(46) Olsson, M. H. M.; Sondergaard, C. R.; Rostkowski, M.; Jensen, J. H. J. Chem. Theory Comput. 2011, 7, 525-537.

(47) Field, M. J.; Albe, M.; Bret, C.; Proust-De Martin, F.; Thomas, A. J. Comput. Chem. 2000, 21, 1088-1100.

(48) Jorgensen, W. L.; Tiradorives, J. J. Am. Chem. Soc. 1988, 110, 1657-1666.

(49) Jorgensen, W. L.; Chandrasekhar, J.; Madura, J. D.; Impey, R. W.; Klein, M. L. J. Chem. Phys. 1983, 79, 926-935.

(50) Phillips, J. C.; Braun, R.; Wang, W.; Gumbart, J.; Tajkhorshid, E.; Villa, E.; Chipot, C.; Skeel, R. D.; Kale, L.; Schulten, K. J. Comput. Chem. 2005, 26, 1781-1802.

(51) Vanommeslaeghe, K.; MacKerell, A. D., Jr. J. Chem. Inf. Model. 2012, 52, 31443154.

(52) Vanommeslaeghe, K.; Raman, E. P.; MacKerell, A. D., Jr. J. Chem. Inf. Model. 2012, 52, 3155-3168.

(53) Vanommeslaeghe, K.; Hatcher, E.; Acharya, C.; Kundu, S.; Zhong, S.; Shim, J.; Darian, E.; Guvench, O.; Lopes, P.; Vorobyov, I.; Mackerell, A. D. J. Comput. Chem. 2010, 31, 671-690.

(54) Field, M. J.; Bash, P. A.; Karplus, M. J. Comput. Chem. 1990, 11, 700-733.

(55) Stewart, J. J. P. J. Comput. Chem. 1989, 10, 209-220.

(56) Nam, K.; Cui, Q.; Gao, J.; York, D. M. J. Chem. Theory Comput. 2007, 3, 486-504.

(57) Corrie, J. E. T.; Barth, A.; Munasinghe, V. R. N.; Trentham, D. R.; Hutter, M. C. J. Am. Chem. Soc. 2003, 125, 8546-8554.

(58) Brandt, W.; Dessoy, M. A.; Fulhorst, M.; Gao, W. Y.; Zenk, M. H.; Wessjohann, L. A. ChemBioChem 2004, 5, 311-323.

(59) Hand, C. E.; Honek, J. F. Bioorg. Med. Chem. Lett. 2007, 17, 183-188.

(60) Plotnikov, N. V.; Prasad, B. R.; Chakrabarty, S.; Chu, Z. T.; Warshel, A. J. Phys. Chem. B 2013, 117, 12807-12819.

(61) Torrie, G. M.; Valleau, J. P. J. Comput. Phys. 1977, 23, 187-199.

(62) Kumar, S.; Bouzida, D.; Swendsen, R. H.; Kollman, P. A.; Rosenberg, J. M. J. Comput. Chem. 1992, 13, 1011-1021.

(63) Corchado, J. C.; Coitino, E. L.; Chuang, Y. Y.; Fast, P. L.; Truhlar, D. G. J. Phys. Chem. A 1998, 102, 2424-2438.

(64) Nguyen, K. A.; Rossi, I.; Truhlar, D. G. J. Chem. Phys. 1995, 103, 5522-5530. 
(65) Chuang, Y. Y.; Corchado, J. C.; Truhlar, D. G. J. Phys. Chem. A 1999, 103, 11401149.

(66) Ruiz-Pernía, J. J.; Silla, E.; Tuñón, I.; Martí, S.; Moliner, V. J. Phys. Chem. B 2004, 108, 8427-8433.

(67) Roca, M.; Moliner, V.; Ruiz-Pernía, J. J.; Silla, E.; Tuñón, I. J. Phys. Chem. A 2006, 110, 503-509.

(68) Ruiz-Pernía, J. J.; Silla, E.; Tuñón, I.; Martí, S. J. Phys. Chem. B 2006, 110, 17663 17670.

(69) Renka, R. J. Siam J. Sci. Stat. Comput. 1987, 8, 393-415.

(70) Renka, R. J. Acm Transact. Math. Software 1993, 19, 81-94.

(71) Frisch, M.; Trucks, G.; Schlegel, H.; Scuseria, G.; Robb, M.; Cheeseman, J.; Scalmani, G.; Barone, V.; Mennucci, B.; Petersson, G.; Nakatsuji, H.; Cariaco, M.; Li, X.; Hratchian, H.; Izmaylov, A.; Bloino, J.; Zheng, G.; Sonnenberg, J.; Hada, M.; Ehara, M.; Toyota, K.; Fukuda, R.; Hasegawa, J.; Ishida, M.; Nakajima, T.; Honda, Y.; Kitao, O.; Nakai, H.; Vreven, T.; Montgomery Jr, J.; Peralta, J.; Ogliaro, F.; Bearpark, M.; Heyd, J.; Brothers, E.; Kudin, K.; Staroverov, V.; Kobayashi, R.; Normand, J.; Raghavachari, K.; Rendell, A.; Burant, J.; Iyengar, S.; Tomasi, J.; Cossi, M.; Rega, N.; Millam, J.; Klene, M.; Knox, J.; Cross, J.; Bakken, V.; Adamo, C.; Jaramillo, J.; Gomperts, R.; Stratmann, R.; Yazyev, O.; Austin, A.; Cammi, R.; Pomelli, C.; Ochterski, J.; RL, M.; Morokuma, K.; Zakrzewski, V.; Voth, G.; Salvador, P.; Dannenberg, J.; Dapprich, S.; Daniels, A.; Farkas, O.; Foresman, J.; Ortiz , J.; Cioslowski, J. a.; Fox, D. Gaussian, Inc., Wallingford CT 2009. 
TOC Graphic

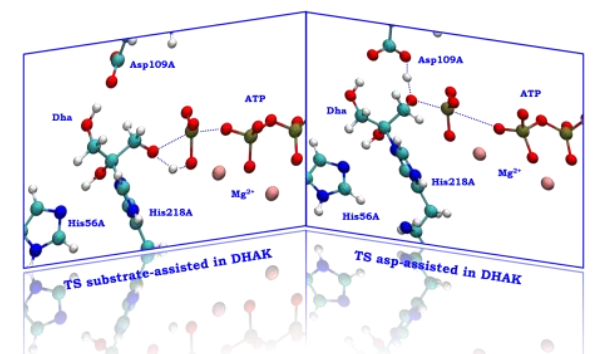

